\title{
A new statistical downscaling approach for global evaluation of the CMIP5 precipitation outputs: model development and application
}

\author{
Qiang Zhang, Zexi Shen, Chong-Yu Xu, Peng Sun, Pan Hu, Chunyang He
} 5

\section{Corresponding author:}

Qiang Zhang, Ph.D., Full Professor,

Key Laboratory of Environmental Changes and Natural Hazards, Ministry of Education (Director), \& Academy of Disaster Reduction and Emergency Management, Ministry of Civil Affairs, Ministry of Education (Dean)

Beijing Normal University,

Beijing 100875,

China.

Tel: +86-10-58807086

E-mail: zhangq68@bnu.edu.cn (preferred contact address)

\section{Corresponding authors:}

Zexi Shen, Mr.

Shentroy@yahoo.com 


\section{A new statistical downscaling approach for global evaluation of the}

\section{CMIP5 precipitation outputs: model development and application}

Qiang Zhang ${ }^{1,2,3}$, Zexi Shen ${ }^{1,2,3}$, Chong-Yu Xu ${ }^{4}$, Peng Sun ${ }^{5}$, Pan $\mathrm{Hu}^{1,2,3}$, Chunyang

$$
\mathrm{He}^{6}
$$

1. Key Laboratory of Environmental Change and Natural Disaster, Ministry of Education, Beijing Normal University, Beijing 100875, China;

2. Faculty of Geographical Science, Academy of Disaster Reduction and Emergency Management, Ministry of Education/Ministry of Civil Affairs, Beijing Normal University, Beijing 100875, China;

3. State Key Laboratory of Earth Surface Processes and Resources Ecology, Beijing Normal University, Beijing 100875, China;

4. Department of Geosciences and Hydrology, University of Oslo, P O Box 1047 Blindern, N-0316 Oslo, Norway;

5. College of Territorial Resource and Tourism, Anhui Normal University, Anhui 241002, China;

6. Center for Human-Environment System Sustainability (CHESS), State Key Laboratory of Earth Surface Processes and Resource Ecology (ESPRE), Beijing Normal University, Beijing 100875, China.

Abstract: Outputs of the Coupled Model Intercomparison Project Phase 5 (CMIP5) models have been widely used in studies of climate changes related to scenarios at global and regional scales. However, CMIP5 outputs cannot be used directly in analysis of climate changes due to coarse spatial resolution. Here, we proposed a new statistical 
downscaling method for the downscaling practice of the CMIP5 outputs, i.e. Biascorrected and station-based Non-linear Regression Downscaling method based on Randomly-Moving Points (BNRD). And up to now, there are only two global downscaled CMIP5 precipitation datasets, i.e. NASA daily downscaled CMIP5 precipitation product and BCSD-based (Bias Correction Spatial Disaggregation) monthly downscaled CMIP5 precipitation product available online, which are both based on BCSD downscaling method. Hence, we evaluated downscaling performance of BNRD by comparing it with the downscaled CMIP5 outputs using the BCSD method in this current study. The results indicate that: (1) during the period for development of the model (1964-2005), the error between downscaled CMIP5 precipitation and GPCC ranges between $-50 \mathrm{~mm} \sim 50 \mathrm{~mm}$ at monthly scale. When compared to BCSDdownscaled CMIP5 precipitation, BNRD-downscaled CMIP5 precipitation well reduces errors and avoids underestimation and overestimation of GPCC by BCSDdownscaled CMIP5 precipitation; (2) during period for verification of the downscaling models (2006-2013), the maximum (182 mm), minimum (15 mm) and average $(68 \mathrm{~mm})$ RMSEs between BNRD-downscaled CMIP5 precipitation and GPCC are all lower than those between BCSD-downscaled CMIP5 precipitation and GPCC at continental scales. Besides, from the average precipitation viewpoint, BNRD-downscaled CMIP5 precipitation is in higher correlation (around 0.75) with GPCC than BCSD-downscaled CMIP5 precipitation under RCP4.5 and RCP8.5 scenarios at continental scales; (3) BNRD resolved the negative relation to GPCC in the areas near equator, including north part of the South America, southern Africa, northern Australia. In all, BNRD 
68

downscaling method developed in this study performs better in describing GPCC changes in both space and time when compared to BCSD and can be used for downscaling practice of CMIP5 and even potentially CMIP6 precipitation outputs over the globe.

Key words: Statistical downscaling; BCSD; BNRD; CMIP5; Precipitation changes

\section{Introduction}

Global warming and relevant impacts on hydrological cycle have aroused growing human concerns in recent decades (Allen and Ingram, 2002; Zhang et al., 2013). Substantial evidences tend to demonstrate intensified precipitation-related extreme events such as drought and floods in both frequency and magnitude (Swain et al., 2018; Nangombe et al., 2018; Samaniego et al., 2018; Fischer et al., 2015). Assessment of potential future changes in water resources and hydrological extremes at regional and global scales is a critical step in understanding impacts of climate changes on hydrological cycle (Li et al., 2016). The outputs of the Coupled Model Intercomparison Project Phase 5 (CMIP5) models have been widely used for this purpose by a range of researches (Taylor et al., 2013; Donat et al., 2016; Li et al., 2017; Song et al., 2018).

However, evaluation of impacts of climate change cannot use outputs of CMIP5 directly due to coarse representation of orography and other elements (Schoof, 2015; Drijfhout et al., 2015). Original version of the outputs of CMIP5 is subject to overestimation and/or underestimation of the attributes (e.g. intensity, frequency and so 
90

91

on) of climatic indicators (such as temperature, precipitation) at global and regional scales and at regional scale in particular (Fyfe et al., 2013; Su et al., 2013; Jiang et al., 2015; Su et al., 2017; Polade et al., 2017; Ham et al., 2018) which necessitate downscaling procedure for CMIP5 outputs. Actually, there stands a range of downscaling methodologies and these methods can be classified into two categories, i.e. dynamical downscaling methods (Hemer et al., 2013; Emanue 2013; Knutson et al., 2015; Jury et al., 2015; Zhang et al., 2018) and statistical downscaling methods (Villarini and Vecchi 2012; Timm et al., 2015; Boisier et al., 2015; Chen et al., 2016; Fyfe et al., 2017; Eum and Cannon 2017). The dynamical and statistical downscaling methods have their own strengths and weaknesses. For example, the dynamic downscaling methods tend to cost considerable computation power (Harding et al., 2013; Glotter et al., 2014; Erler et al., 2015). Statistical downscaling methods can produce similarly accurate outputs when compared to those by dynamical downscaling techniques (Le et al., 2018). Hence, when it comes to downscaling workload at larger spatial scale such as continental and even global scale, statistical downscaling methods are preferred.

There are various downscaled CMIP5 datasets with focus on continental and regional scales (i.e. U.S.), e.g. the ClimateNA developed by AdaptWest, NASA NEXDCP30 developed by NASA, MACAv2-LIVNEH developed by Livneh's team (Livneh et al., 2013), and these datasets are all for the North America (Jiang et al., 2018). So far, only one published downscaled CMIP5 dataset (https://gdo-dcp.ucllnl.org) was produced by the U.S. Department of the Interior, Bureau of Reclamation, using the Bias 
112

Correction Spatial Disaggregation (BCSD) method. To enhance availability of the downscaled CMIP5 dataset and also availability of new downscaling technique, here we proposed a new statistical downscaling technique, i.e. Bias-corrected Non-linear Regression Downscaling method using Station-based Randomly-Moving Points (BNRD). Different from previous grid-by-grid statistical downscaling methods, we considered the altitude of randomly-generated spatial points and classified them into 4 6 groups with moving window of size of $9^{\circ} \times 9^{\circ}$. From the viewpoint of computation cost, in comparison with dynamical downscaling methods, statistical downscaling methods, i.e. BNRD, own particular strengths in computation speed, which has been widely evidenced (Harding et al., 2013; Glotter et al., 2014; Erler et al., 2015; Le et al., 2018). Besides, BNRD is based on sample points that are selected by locations (longitude and latitude) and altitude attributions within all of sub-windows that cover the continents over the globe. In this way, we only need to conduct the downscaling procedure for every single sample point, and then interpolate the sample-based downscaling results to grid scale with required spatial resolution. Hence, in comparison with downscaling for every single grid cell, BNRD, based on sample points with particular attributions, will save computation time.. Meanwhile, we also included the altitude information into the downscaling procedure and hence the downscaled precipitation data will involve impacts of topography on spatial patterns of precipitation changes. This point constitutes the major advantage of the newly-proposed downscaling method in this study over the standing downscaling methods. Besides, downscaling performance of the BNRD was verified by comparisons between downscaled 
134

135

precipitation datasets by the BCSD, GPCC precipitation data (precipitation dataset produced by the Global Precipitation Climatology Centre) (Rudolf et al., 2009; Sun et al., 2018) and the BNRD.

Therefore, the major objectives of this study are to (1) propose a new statistical downscaling method considering impacts of altitude and also reduction of cost power; (2) to verify the downscaling performance of the BNRD in comparison with downscaled precipitation datasets by BCSD and GPCC precipitation dataset; and (3) to produce a new version of the global downscaled CMIP5 precipitation datasets under RCP4.5 and RCP8.5 scenarios. This study can help to provide a new theoretical angle in downscaling analysis and also new downscaling procedure for downscaling practice of precipitation at global scale.

\section{Data}

In this study, 25 raw CMIP5 precipitation outputs (Table 1) (http://data.ceda.ac.uk) by the Centre for Environmental Data Analysis (CEDA) were included in the analyses (https://gdo-dcp.ucllnl.org/) with coarse spatial resolution and monthly temporal resolution. Besides, we also collected gauge-based reanalysis precipitation product produced by Global Precipitation Climatology Centre (GPCC), with spatial resolution as $0.5^{\circ} \times 0.5^{\circ}$ and temporal resolution as month (https://www.esrl.noaa.gov). And 25 BCSD downscaled CMIP5 precipitation outputs have been developed by the U.S. Department of the Interior, Bureau of Reclamation, Technical Services Center and published online (https://gdo-dcp.ucllnl.org/). Up to now, global-downscaled CMIP5 
156

157

precipitation products are rare. And there are NASA daily downscaled CMIP5 precipitation product and aforementioned BCSD-based monthly downscaled CMIP5 precipitation product available online. And they are all based on BCSD downscaling method, which demonstrates BCSD downscaling method is more practical than other methods. Hence, we directly employed this dataset as comparison group to verify and intercompare the performance and accuracy of BNRD downscaled CMIP5 precipitation on detecting the observed precipitation. The historical period in this study refers to the period of 1964-2005, and the validation period refers to the period of 2006-2013.

\section{Development of the new statistical downscaling method}

The developed BNRD technique includes the following modules: the randomlymoving-points module, the station-based downscaling module and the bias correction module. Besides, we evaluated the downscaling performance of the BNRD using the Pearson correlation analysis and the root mean square error (RMSE) methods (Geil et al., 2013; Sheffield et al, 2013; Gagen et al., 2016; Aloysius et al., 2016; Lovino et al., 2018).

\subsection{Randomly-moving-points mechanism}

Here, we proposed a new algorithm named Randomly-Moving Points (RMP), which is based on the spatial attributes of the points selected for computation such as longitude, latitude and altitude (Fig. 1). The first step of this algorithm is to extract a sub-window with size of $9^{\circ} \times 9^{\circ}$ based on the DEM map. In this study, we separated the land and ocean by assigning NA, i.e. not available, to the DEM value of oceanic area. On the second step, within the sub-window, we generated 500 random points by 
178

179

generating random longitude and latitude values using rnorm function within $\mathrm{R}$ (Johnson and Kotz, 1970; Kinderman and Monahan, 1977), which obeys Gaussian distribution (Thomas et al., 2007), within the scale of sub-window. To screen out the points located in the oceanic regions, we selected the points with available altitude information. Further, considering relations between altitude and precipitation and poor performance of CMIP5 outputs in describing precipitation changes in mountainous zones (Su et al., 2013; Mehran et al., 2014), we grouped the land points within the subwindow into four to six categories with equal step calculated based on difference between the maximum and minimum altitude value within the sub-window. However, the absolute maximum and minimum altitude values shift from one sub-window to another, therefore, altitude intervals were determined for each individual sub-window respectively. Final step is to select the points from each group with certain altitudes and the total number of points was limited to 7-10 for each sub-window. The sub-windows move along the latitudinal direction with steps of $3^{\circ}$ and the total number of subwindows is 552 with exception of the sub-windows full of the oceanic regions.

\subsection{Station-based non-linear regression downscaling (SNRD) analysis}

In this study, the GPCC precipitation during 1964-2005 was used for model development and GPCC precipitation during 2006-2013 for model validation. The CMIP5 outputs during same periods were also used for model development and model validation. Preliminary analysis of relations between CMIP5 outputs and GPCC precipitation shows a nonlinear behavior. Therefore, we proposed a station-based non- 
199

200

201

202

203

204

205

linear regression (SNR) model to downscale CMIP5 precipitation outputs to the scale of sample point:

$$
\operatorname{Pred}_{\operatorname{pr}(i, j, z, t)}=a_{(i, j, z, t)} \times \frac{\left.C M I P 5_{\operatorname{pr}(i, j, z, t)}\right)^{2}}{1 \mathrm{~mm}}+b_{(i, j, z, t)} \times C M I P 5_{\operatorname{pr}(i, j, z, t)}+\varepsilon_{(i, j, z, t)}
$$

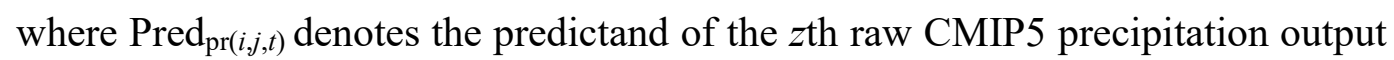
at the point $j$ on the $t$ th month under the $i$ th $\mathrm{RCP}$ scenario and the unit is $\mathrm{mm}$; CMIP $5_{\operatorname{pr}(i, j, z, t)}$ is the $z$ th original CMIP5 precipitation output at the point $j$ on the $t$ th month under the $i$ th scenario (including historical scenario for model development and RCP4.5 and RCP8.5 scenarios for model validation), with unit as mm; $\varepsilon_{i, j, z, t}$ denotes the residual and the unit is $\mathrm{mm} ; a$ and $b$ refer to the parameters of the function.

\subsection{Bias correction}

In bias correction analysis, we defined and used the monthly precipitation pattern. Based on the occurrence time of the maximum precipitation amount within a given year, we classified the monthly precipitation patterns into four types: January to March, April to June, July to September and October to December (Fig. 2). We compared the precipitation pattern of GPCC during 1964-1999 at aforementioned four types of sample points with that of CMIP5 precipitation outputs during 2064-2099 under RCP4.5 and RCP8.5 scenarios. It is interesting to find no significant differences in monthly precipitation pattern and monthly precipitation amount under historical, RCP4.5 and RCP8.5 scenarios for all sample points (Figs. 3-4). We can use historical monthly precipitation differences between GPCC and 25 CMIP5 indices to project the spatial and temporal pattern of the monthly precipitation differences between future in situ precipitation observations and 25 CMIP5 precipitation indices. Therefore, we can 
221

222

generate the bias correction matrix based on the monthly precipitation pattern of the historical GPCC and 25 CMIP5 precipitation in this study.

The procedure of the bias correction includes the following steps: (1) monthly historical precipitation pattern analysis of GPCC and 25 SNRD-processed CMIP5 precipitation outputs to compute the monthly precipitation index from January to December during 1964-2005 at the sample points; (2) generation of bias correction vector using the difference between GPCC precipitation index and 25 CMIP5 precipitation outputs reprocessed by the SNRD at the sample points; (3) generation of the bias correction matrix for the validation period (2006-2013) by iterating the 25 CMIP5 bias correction vectors for all sample points; (4) bias correction by applying 25 SNRD-processed CMIP5 precipitation indices and 25 CMIP5 bias correction matrices accordingly. Taking SNRD-processed ACCESS1-0 for an example (subB-a, c, e, g in Fig. 1), we firstly analyzed monthly GPCC and SNRD-processed ACCESS1-0 precipitation patterns for all four types of sample points on behalf of aforementioned four specific precipitation patterns. Then, we assumed that the monthly precipitation patterns would not shift with time under different RCP scenarios and used the difference between GPCC monthly average precipitation during 1964-2005 and the SNRDprocessed monthly average precipitation under ACCESS1-0 to generate the bias correction vector within a year (from January to December). In addition, according to the time span for the validation period of BNRD downscaling model (2006-2013, monthly), we assumed that the bias correction vector would not change annually and then we generated the bias correction matrix (subB-b, d, f, $\mathrm{h}$ in Fig. 1 denote the bias 
243

244

correction matrices of four sample points respectively) by repeating the aforementioned bias correction vector row by row with number of rows equals to the time span of validation period (2006-2013). Finally, we added the bias correction matrix to each SNRD-processed ACCESS1-0 precipitation index and the entire bias correction procedure was done. After the bias correction section, downscaling results were spatially interpolated to downscaled resolution $\left(0.5^{\circ} \times 0.5^{\circ}\right)$ using Kriging interpolation method (Timm et al., 2015).

\subsection{Downscaling performance evaluation using statistical methods}

To evaluate the modeling accuracy of the BNRD-based downscaling precipitation results for 25 CMIP5 precipitation outputs, BCSD-based globally-downscaled precipitation products for 25 CMIP5 precipitation outputs have been taken as control group. Root mean square errors (RMSE) and Pearson correlation analysis method have been accepted to evaluate precipitation downscaling accuracy of the BNRD method (Geil et al., 2013; Sheffield et al, 2013; Aloysius et al., 2016; Gagen et al., 2016; Lovino et al., 2018).

\section{Results and discussions}

\subsection{BNRD-downscaled CMIP5 precipitation outputs across the continent during}

\section{4-2005}

To evaluate the performance of the downscaling models considered in this study for 25 CMIP5 precipitation outputs, i.e. SNRD, BNRD and BCSD, we firstly calculated the average precipitation for each continent such as Africa, Asia, Europe, North 
265

266

267

America, Oceania and South America based on 25 raw CMIP5 precipitation outputs and downscaled precipitation outputs by SNRD, BNRD and BCSD, respectively. Modeling accuracy of the downscaled 25 CMIP5 precipitation outputs can be evaluated based on the difference between the average CMIP5 precipitation minus GPCC precipitation. We can find overestimation and/or underestimation of the GPCC by the CMIP5 precipitation outputs due to coarse spatial resolution of the CMIP5 precipitation outputs (Fig. 5). Therefore, CMIP5 precipitation outputs cannot be used directly for climate variability analysis (Drijfhout, 2005; Schoof, 2015). In this sense, downscaling procedure of the CMIP5 precipitation outputs is technically critical.

Here, we intercompared the precipitation biases of the downscaled precipitation outputs by three downscaling methods, i.e. SNRD, BNRD and BCSD during 19642005 when compared to GPCC on the continent scale. The precipitation biases by the SNRD method tend to enlarged during certain months and those by BNRD method distribute evenly from one month to another in Africa, Asia, Europe, North America and South America. Besides, Fig. 5 also indicates the reduced precipitation bias by BNRD within $-50 \mathrm{~mm}$ and $50 \mathrm{~mm}$ across continents with exception of the Oceania, and in Asia and North America in particular with precipitation bias of nearly $0 \mathrm{~mm}$. Different from BNRD is the significant overestimation (Oceania and South America) and/or underestimation (Africa and Asia) of GPCC by the BCSD. BNRD method greatly reduces overestimation of the GPCC precipitation during May to September and produces statistically good estimation of the GPCC during January to April. In contrast, BCSD method enlarges overestimation tendency of the original CMIP5 precipitation 
287

288

outputs from 0-75 mm to 100-150 mm during April-September in Oceania (Fig. 5). In this sense, BNRD performs better than BCSD in downscaling the original CMIP5 precipitation outputs during 1964-2005 at continental scale.

\subsection{Intercomparison of RMSE between original and downscaled CMIP 5} precipitation outputs during 2006-2013 on the continent scale

We computed the RMSE between the 25 raw CMIP5 precipitation outputs, BNRDand BCSD-downscaled CMIP5 precipitation outputs, and GPCC data within each continent during 2006-2013 under both RCP4.5 and RCP8.5 scenarios. Within each continent on the point scale, RMSEs have been analyzed for minimum, maximum and mean values. Fig. 6 indicates intercomparison of the RMSEs between the GPCC and the downscaled CMIP5 precipitation outputs using BCSD and BNRD, and the original CMIP5 precipitation outputs respectively under RCP4.5 and RCP8.5 scenarios. The RMSEs between BNRD-downscaled CMIP5 precipitation outputs and the GPCC reach the lowest values, e.g. around $15 \mathrm{~mm}, 182 \mathrm{~mm}$ and $68 \mathrm{~mm}$ under both RCP scenarios, which are far less than the RMSEs between GPCC and the original CMIP5 outputs, i.e. around $30 \mathrm{~mm}, 901 \mathrm{~mm}$ and $121 \mathrm{~mm}$ under both RCP scenarios, and the RMSEs between GPCC and the BCSD-downscaled CMIP5 outputs, i.e. around $164 \mathrm{~mm}, 420$ $\mathrm{mm}$ and $241 \mathrm{~mm}$ under RCP4.5 scenario and around $165 \mathrm{~mm}, 516 \mathrm{~mm}$ and $280 \mathrm{~mm}$ under RCP8.5 scenario. Therefore, BNRD has the better downscaling performance when compared to BCSD.

Besides, we intercompared the averaged GPCC, the averaged 25 raw CMIP5 precipitation outputs, and the averaged BCSD- and BNRD-downscaled CMIP5 
309

310

precipitation outputs during 2006-2013 at the continental scale, i.e. the validation period for downscaling models considered in this study, under RCP4.5 and RCP8.5 scenarios (Fig. 7). Fig. 7 shows that the averaged BNRD-downscaled precipitation data follow close to the GPCC for each continent. In contrast, BCSD-downscaled CMIP5 precipitation outputs are close to the GPCC data in the North America and Europe only. When it comes to other continents, BCSD-downscaled CMIP5 precipitation outputs tend to significantly deviate the GPCC data, implying underestimation (Africa and Asia) and/or overestimation (Oceania and South America) of the GPCC. All these results clearly indicate better downscaling performance of BNRD than BCSD. Besides, BNRD has more reliable downscaling performance than BCSD.

\subsection{Pearson correlation between GPCC and downscaled CMIP5 precipitation} outputs by BNRD and BCSD respectively during 2006-2013 on the continent scale

Fig. 8 displays Pearson correlation coefficients (PCC) between BNRD- and BCSDdownscaled CMIP5 precipitation outputs and GPCC under RCP4.5 and RCP8.5 scenarios. In this study, significance of the PCCs was tested at 0.05 significance level. It can be seen from Fig. 8 that the lowest PCCs between BNRD-downscaled and the GPCC over all the continents under RCP scenarios are around 0.750 , which is significantly larger than the lowest PCCs between BCSD-downscaled and the GPCC over all the continents under RCP scenarios, i.e. 0.14 under RCP4.5 and 0.034 under RCP8.5. To compare the PCCs between BCSD- and BNRD-downscaled CMIP5 precipitation outputs and the GPCC in a direct way, we used the PCC matrix obtained 
331

332

by difference between PCCs between BNRD- downscaled CMIP5 precipitation outputs and the GPCC (PCC-BNRD), and PCCs between BCSD-downscaled CMIP5 precipitation outputs and the GPCC (PCC-BCSD) (Fig. 9). Fig. 9 indicates the difference of PCCs as mentioned above reaches the low-value ranges $(<0.2)$ in the Asia and the North America under RCP4.5 and RCP8.5 scenarios, implying that the BNRD method is similar to the BCSD in downscaling the tendency of the measured precipitation under RCP4.5 and RCP8.5 scenarios. However, PCC-BNRD values are greater than PCC-BCSD in the Oceania and South America, which demonstrates that BNRD-downscaled CMIP5 precipitation outputs can well capture changing properties of the measured precipitation as reflected by GPCC datasets.

\subsection{Intercomparison of PCCs in spatial distribution}

To compare PCCs between BNRD- and BCSD-downscaled CMIP5 precipitation outputs and GPCC under RCP4.5 and RCP8.5 scenarios (simply BNRD-GPCC, and BCSD-GPCC in the subsequent text) in spatial distribution, we interpolated the BNRDGPCC and BCSD-GPCC by Kriging interpolation method (Figs. 10-11 for RCP4.5 scenario, Figs. 13-14 forRCP8.5 scenario). Further, comparison was done on the difference between BNRD-GPCC and BCSD-GPCC over the globe (Figs. 12 and 15).

Under RCP4.5 scenario, both BNRD-GPCC and BCSD-GPCC are significantly high, e.g. BNRD-GPCC is higher than 0.7 and BCSD-GPCC is higher than 0.5 in most areas of North America, Europe and Asia (Figs. 10-11). However, in northern parts of the South America, most areas of the South Africa and northern parts of the Australia, BCSD-GPCC values are negative (Fig. 11). In contrast, BNRD-downscaled CMIP5 
353

354

precipitation outputs describe the GPCC changes in a right way with BNRD-GPCC values of higher than 0.75 (Fig. 10), which is also highlighted by remarkable difference (greater than 1.0) between PCC-BNRD and PCC-BCSD (Fig. 12). Besides, in central parts of the Greenland, BCSD-GPCC values are negative, i.e. -0.5 - 0. In contrast, BNRD-GPCC are not negative in these regions. Therefore, BNRD performs better than BCSD in downscaling CMIP5 precipitation in most regions. Under RCP8.5 scenario, spatial patterns of the BNRD-GPCC and BCSD-GPCC under RCP8.5 are in good agreement with those under RCP4.5 scenario (Figs. 10-15). In general, under RCP4.5 and RCP8.5 scenarios, in comparison with BCSD, BNRD greatly improves the downscaling results of the CMIP5 precipitation outputs from global viewpoint and the downscaled CMIP5 precipitation outputs by BNRD can well describe GPCC precipitation changes over the globe.

\section{Conclusions}

In this study, we proposed the BNRD downscaling method and the downscaling performance of BNRD was verified and corroborated via comparison with downscaling performance of the BCSD. We obtained interesting and important findings and conclusions as follows:

(1) During 1964-2005, the period for model development, BCSD-downscaled CMIP5 precipitation is nearly the same as GPCC just in North America and Europe. In contrast, BNRD-downscaled CMIP5 precipitation can well describe the GPCC changes 
374

over the globe and avoid overestimating (in South America and Oceania) and/or underestimating (in Asia and Africa) GPCC precipitation.

(2) During the period for the model validation, i.e. 2006-2013 under RCP4.5 and RCP8.5 scenarios, the maximum, minimum and average RMSEs between BNRDdownscaled CMIP5 precipitation and GPCC are respectively $182 \mathrm{~mm}, 15 \mathrm{~mm}$ and 68 $\mathrm{mm}$, and are all lower than that between BCSD-downscaled CMIP5 precipitation and GPCC. From the average precipitation viewpoint, during the period for model verification under RCP4.5 and RCP8.5 scenarios, the BNRD-downscaled CMIP5 precipitation is in higher correlation with GPCC than BCSD-downscaled CMIP5 precipitation. While, the BCSD-downscaled CMIP5 precipitation is in negative bias from GPCC across Africa and Asia and is in positive bias from GPCC across Oceania and South America. Therefore, BNRD-downscaled CMIP5 precipitation can better describe GPCC in both space and time when compared to BCSD.

(3) We found higher correlation between BNRD-downscaled CMIP5 precipitation and GPCC than between BCSD-downscaled CMIP5 precipitation and GPCC globally. From a viewpoint of the spatial distribution of GPCC-BCSD minus GPCC-BNRD, the difference between GPCC-BNRD and GPCC-BCSD is even larger than 1 over north part of the South America, southern Africa, northern Australia, implying negative relations between BCSD-downscaled CMIP5 precipitation and GPCC. While, BNRDdownscaled CMIP5 precipitation and GPCC is in positive correlation in these continents. All these results further corroborate greatly improved downscaling performance of BNRD when compared to that of BCSD. This study provides improved 
396

397

398

399

400

401

402

403

404

405

406

407

408

409

410

411

412

413

414

415

416

417

downscaling technique for downscaling practice of CMIP5 and even CMIP6 precipitation outputs over the globe.

Acknowledgement: This work is financially supported by the National Science Foundation for Distinguished Young Scholars of China (Grant No. 51425903), National Natural Science Foundation of China (No. 41771536), the Research Council of Norway (FRINATEK Project 274310), and by National Natural Science Foundation of China (No. 41701103). Our cordial gratitude should be extended to the editor, Prof. Dr. Pingqing $\mathrm{Fu}$, and anonymous reviewers for their professional and pertinent comments which are greatly helpful for further quality improvement of this current manuscript.

\section{Reference:}

Allen, M. R., Ingram, W. J., 2002. Constraints on future changes in climate and the hydrologic cycle. Nature 419(6903), 224-232.

Aloysius, N. R., Sheffield, J., Saiers, J. E., Li, H., Wood, E. F., 2016. Evaluation of historical and future simulations of precipitation and temperature in central Africa from CMIP5 climate models. Journal of Geophysical Research: Atmospheres 121(1), 130-152.

Boisier, J. P., Ciais, P., Ducharne, A., Guimberteau, M., 2015. Projected strengthening of Amazonian dry season by constrained climate model simulations. Nature Climate Change 5(7), 656-660.

Chen, Y. D., Li, J., Zhang, Q., 2016. Changes in site - scale temperature extremes over 
China during 2071-2100 in CMIP5 simulations. Journal of Geophysical Research: Atmospheres 121(6), 2732-2749.

Donat, M. G., Lowry, A. L., Alexander, L. V., O’Gorman, P. A., Maher, N., 2016. More extreme precipitation in the world's dry and wet regions. Nature Climate Change 6(5), 508-513.

Drijfhout, S., Bathiany, S., Beaulieu, C., Brovkin, V., Claussen, M., Huntingford, C., Scheffer, M., Sgubin, G., Swingedouw, D., 2015. Catalogue of abrupt shifts in Intergovernmental Panel on Climate Change climate models. Proceedings of the National Academy of Sciences 112(43), E5777-E5786.

Emanuel, K. A., 2013. Downscaling CMIP5 climate models shows increased tropical cyclone activity over the 21st century. Proceedings of the National Academy of Sciences 110(30), 12219-12224.

Erler, A. R., Peltier, W. R., D’Orgeville, M., 2015. Dynamically downscaled highresolution hydroclimate projections for western Canada. Journal of Climate 28(2), 423-450.

Eum, H. I., Cannon, A. J., 2017. Intercomparison of projected changes in climate extremes for South Korea: application of trend preserving statistical downscaling methods to the CMIP5 ensemble. International Journal of Climatology 37(8), $3381-3397$.

Fischer, E. M., Knutti, R., 2015. Anthropogenic contribution to global occurrence of heavy-precipitation and high-temperature extremes. Nature Climate Change 5(6), $560-564$. 
440

441

442

443

444

445

446

447

448

449

450

451

452

453

454

455

456

457

458

459

460

461

Fyfe, J. C., Derksen, C., Mudryk, L., Flato, G. M., Santer, B. D., Swart, N. C., Molotch, P., N., Zhang, X., Wan, H., Arora, K. V., Scinocca, J., Jiao, Y., 2017. Large nearterm projected snowpack loss over the western United States. Nature Communications 8, 14996.

Fyfe, J. C., Gillett, N. P., Zwiers, F. W., 2013. Overestimated global warming over the past 20 years. Nature Climate Change 3(9), 767-769.

Gagen, M. H., Zorita, E., McCarroll, D., Zahn, M., Young, G. H., Robertson, I., 2016. North Atlantic summer storm tracks over Europe dominated by internal variability over the past millennium. Nature Geoscience 9(8), 630-635.

Geil, K. L., Serra, Y. L., Zeng, X., 2013. Assessment of CMIP5 model simulations of the North American monsoon system. Journal of Climate 26(22), 8787-8801.

Glotter, M., Elliott, J., McInerney, D., Best, N., Foster, I., Moyer, E. J., 2014. Evaluating the utility of dynamical downscaling in agricultural impacts projections. Proceedings of the National Academy of Sciences 111(24), 8776-8781.

Ham, Y. G., Kug, J. S., Choi, J. Y., Jin, F. F., Watanabe, M., 2018. Inverse relationship between present-day tropical precipitation and its sensitivity to greenhouse warming. Nature Climate Change 8(1), 64-69.

Harding, K. J., Snyder, P. K., Liess, S., 2013. Use of dynamical downscaling to improve the simulation of Central US warm season precipitation in CMIP5 models. Journal of Geophysical Research: Atmospheres 118(22), 12-522.

Hemer, M. A., Fan, Y., Mori, N., Semedo, A., Wang, X. L., 2013. Projected changes in wave climate from a multi-model ensemble. Nature Climate Change 3(5), 471-476. 
462

463

464

465

466

467

468

469

470

471

472

473

474

475

476

477

478

479

480

481

482

483

Huang, J., Yu, H., Dai, A., Wei, Y., Kang, L., 2017. Drylands face potential threat under 2 C global warming target. Nature Climate Change 7(6), 417-422.

Jiang, Y., Kim, J. B., Still, C. J., Kerns, B. K., Kline, J. D., Cunningham, P. G., 2018. Inter-comparison of multiple statistically downscaled climate datasets for the Pacific Northwest, USA. Scientific Data 5, 180016.

Jiang, Z., Li, W., Xu, J., Li, L., 2015. Extreme precipitation indices over China in CMIP5 models. Part I: Model evaluation. Journal of Climate 28(21), 8603-8619.

Jury, M. W., Prein, A. F., Truhetz, H., Gobiet, A., 2015. Evaluation of CMIP5 models in the context of dynamical downscaling over Europe. Journal of Climate 28(14), 5575-5582.

Johnson, N. L., \& Kotz, S. (1971). Univariate continuous distributions: distributions in statistics Vol 1 and 2.

Knutson, T. R., Sirutis, J. J., Zhao, M., Tuleya, R. E., Bender, M., Vecchi, G. A., Villarini, G., Chavas, D., Chavas, D., 2015. Global projections of intense tropical cyclone activity for the late twenty-first century from dynamical downscaling of CMIP5/RCP4. 5 scenarios. Journal of Climate 28(18), 7203-7224.

Kinderman, A. J., \& Monahan, J. F. (1977). Computer generation of random variables using the ratio of uniform deviates. ACM Transactions on Mathematical Software (TOMS), 3(3), 257-260.

Le Roux, R., Katurji, M., Zawar-Reza, P., Quénol, H., Sturman, A., 2018. Comparison of statistical and dynamical downscaling results from the WRF model. Environmental Modeling \& Software 100, 67-73. 
484

485

486

487

488

489

490

491

492

493

494

495

496

497

498

499

500

501

502

503

504

505

Li, G., Xie, S. P., He, C., Chen, Z., 2017. Western Pacific emergent constraint lowers projected increase in Indian summer monsoon rainfall. Nature Climate Change 7(10), 708-712.

Li, J., Y.D. Chen, L. Zhang, Q. Zhang, and Francis H.S. Chiew, 2016. Future changes in floods and water availability across China: Linkage with changing climate and uncertainties. Journal of Hydrometeorology 17, 1295-1314.

Livneh, B., Rosenberg, E. A., Lin, C., Nijssen, B., Mishra, V., Andreadis, K. M., Maurer, E. P., Lettenmaier, D. P., 2013. A long-term hydrologically based dataset of land surface fluxes and states for the conterminous United States: Update and extensions. Journal of Climate 26(23), 9384-9392.

Lopez, H., West, R., Dong, S., Goni, G., Kirtman, B., Lee, S. K., Atlas, R., 2018. Early emergence of anthropogenically forced heat waves in the western United States and Great Lakes. Nature Climate Change 8, 414-420.

Lovino, M. A., Müller, O. V., Berbery, E. H., Müller, G. V., 2018. Evaluation of CMIP5 retrospective simulations of temperature and precipitation in northeastern Argentina. International Journal of Climatology 38, e1158-e1175.

McGregor, S., Stuecker, M. F., Kajtar, J. B., England, M. H., Collins, M., 2018. Model tropical Atlantic biases underpin diminished Pacific decadal variability. Nature Climate Change 8, 493-498.

Mehran, A., AghaKouchak, A., Phillips, T. J., 2014. Evaluation of CMIP5 continental precipitation simulations relative to satellite-based gauge-adjusted observations. Journal of Geophysical Research: Atmospheres 119(4), 1695-1707. 
506

507

508

509

510

511

512

513

514

515

516

517

518

519

520

521

522

523

524

525

526

527

Nangombe, S., Zhou, T., Zhang, W., Wu, B., Hu, S., Zou, L., Li, D., 2018. Recordbreaking climate extremes in Africa under stabilized $1.5^{\circ} \mathrm{C}$ and $2^{\circ} \mathrm{C}$ global warming scenarios. Nature Climate Change 8(5), 375-380.

Pfahl, S., O’Gorman, P. A., Fischer, E. M., 2017. Understanding the regional pattern of projected future changes in extreme precipitation. Nature Climate Change 7(6), 423-427.

Polade, S. D., Gershunov, A., Cayan, D. R., Dettinger, M. D., Pierce, D. W., 2017. Precipitation in a warming world: Assessing projected hydro-climate changes in California and other Mediterranean climate regions. Scientific Reports 7(1), 1-10.

Rudolf, B., Becker, A., Schneider, U., Meyer-Christoffer, A., Ziese, M., 2010. The new “GPCC Full Data Reanalysis Version 5” providing high-quality gridded monthly precipitation data for the global land-surface is public available since December 2010. GPCC Status rep.

Samaniego, L., Thober, S., Kumar, R., Wanders, N., Rakovec, O., Pan, M., Zink, M., Sheffield, J., Wood, E. F., Marx, A., 2018. Anthropogenic warming exacerbates European soil moisture droughts. Nature Climate Change 8(5), 421-426.

Schoof, J. T., 2015. High - resolution projections of 21 st century daily precipitation for the contiguous US. Journal of Geophysical Research: Atmospheres 120(8), 30293042.

Sheffield, J., Barrett, A. P., Colle, B., Nelun Fernando, D., Fu, R., Geil, K. L.,Hu, Q., Kinter, J., Kumar, S., Langenbrunner, B., Lombardo, K., Long, L.N., Maloney, E., Mariotti, A., Meyerson, J.E., Mo, K.C., Neelin, J.D., Nigam, S., Pan, Z., Ren, T., 
Ruiz-Barradas, A., Serra, Y.L., Seth, A., Thibeault, J.M., Stroeve, J.C., Yang, Z., Yin, L., 2013. North American climate in CMIP5 experiments. Part I: Evaluation of historical simulations of continental and regional climatology. Journal of Climate 26(23), 9209-9245.

Song, F., Leung, L. R., Lu, J., Dong, L., 2018. Seasonally dependent responses of subtropical highs and tropical rainfall to anthropogenic warming. Nature Climate Change 8(9), 787-792.

Su, F., Duan, X., Chen, D., Hao, Z., Cuo, L., 2013. Evaluation of the global climate models in the CMIP5 over the Tibetan Plateau. Journal of Climate 26(10), 31873208.

Su, H., Jiang, J. H., Neelin, J. D., Shen, T. J., Zhai, C., Yue, Q., Wang, Z., Huang, L., Choi, Y.S., Stephens, G.L., Yung, Y. L., 2017. Tightening of tropical ascent and high clouds key to precipitation change in a warmer climate. Nature Communications 8, 15771.

Sun, Q., Miao, C., Duan, Q., Ashouri, H., Sorooshian, S., Hsu, K. L., 2018. A review of global precipitation data sets: Data sources, estimation, and intercomparisons. Reviews of Geophysics 56(1), 79-107.

Swain, D. L., Langenbrunner, B., Neelin, J. D., Hall, A., 2018. Increasing precipitation volatility in twenty-first-century California. Nature Climate Change 8(5), 427-433.

Taylor, K. E., Stouffer, R. J., Meehl, G. A., 2012. An overview of CMIP5 and the experiment design. Bulletin of the American Meteorological Society 93(4), 485498. 
550

551

552

553

554

555

556

557

558

559

560

561

562

563

564

565

566

567

Thomas, D. B., Luk, W., Leong, P. H., Villasenor, J. D., 2007. Gaussian random number generators. ACM Computing Surveys (CSUR) 39(4), 11.

Timm, O. E., Giambelluca, T. W., Diaz, H. F., 2015. Statistical downscaling of rainfall changes in Hawaii based on the CMIP5 global model projections. Journal of Geophysical Research: Atmospheres 120(1), 92-112.

Villarini, G., Vecchi, G. A., 2012. Twenty-first-century projections of North Atlantic tropical storms from CMIP5 models. Nature Climate Change 2(8), 604-607.

Watanabe, M., Kamae, Y., Shiogama, H., DeAngelis, A. M., Suzuki, K., 2018. Low clouds link equilibrium climate sensitivity to hydrological sensitivity. Nature Climate Change 8(10), 901-906.

Wu, P., Christidis, N., Stott, P., 2013. Anthropogenic impact on Earth's hydrological cycle. Nature Climate Change, 3(9), 807-810.

Zhang, Q., J. Li, V.P. Singh, M. Xiao, 2013. Spatio-temporal relations between temperature and precipitation regimes: Implications for temperature-induced changes in the hydrological cycle. Global and Planetary Change 111, 57-76.

Zhang, Z., Colle, B. A., 2018. Impact of Dynamically Downscaling Two CMIP5 Models on the Historical and Future Changes in Winter Extratropical Cyclones along the East Coast of North America. Journal of Climate 31(20), 8499-8525. 


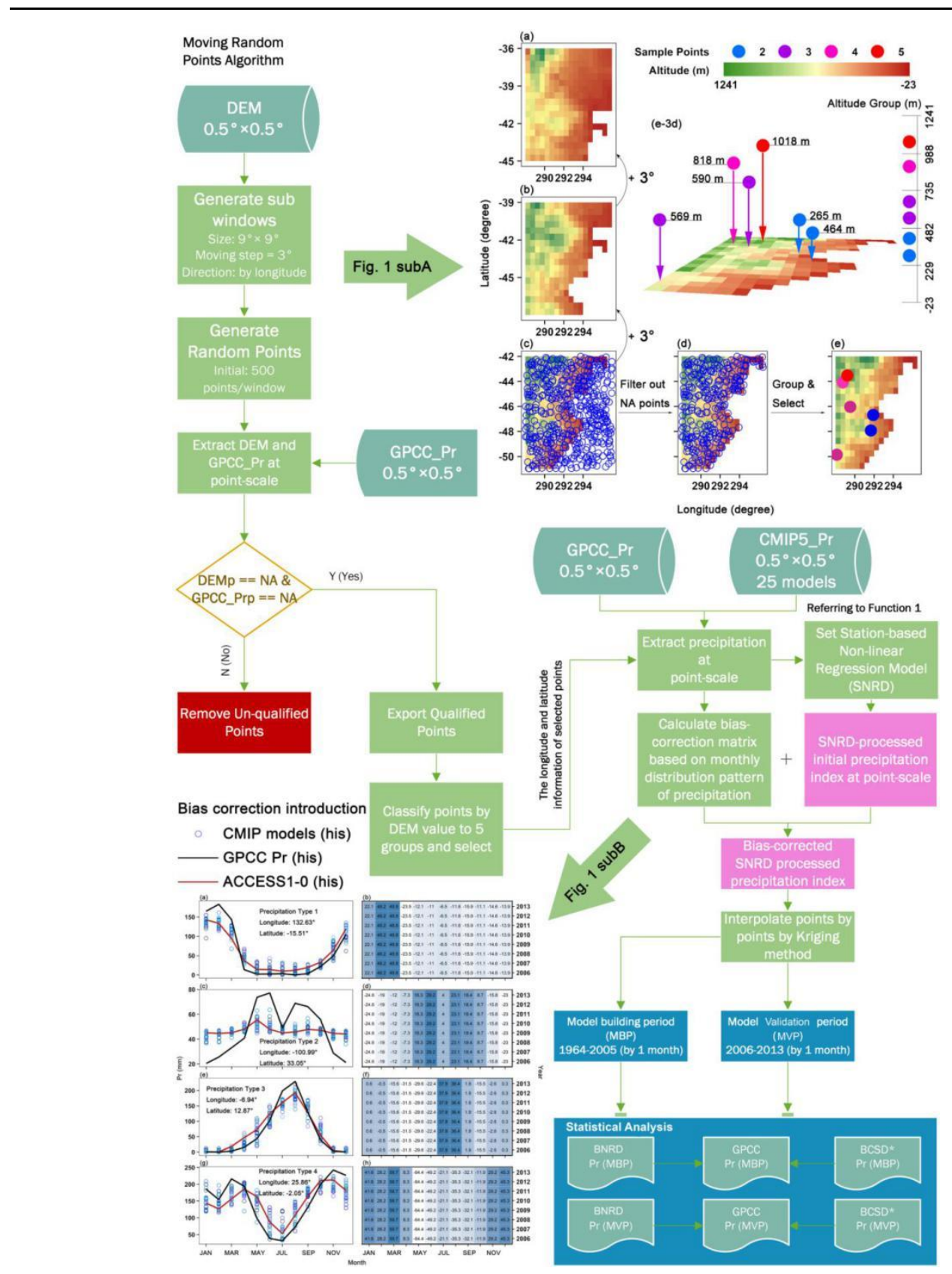

Fig. 1 The algorithm frame of Moving-Random-Points generated and Bias-Corrected Station-based Non-linear Regression Downscaling model (BNRD for short). DEM refers to the digital elevation model and its spatial resolution is 0.5 degree. GPCC_Pr refers to the gridded measured precipitation datasets generated by the Global Precipitation Climatology Center (GPCC) and its spatiotemporal resolution is month and 0.5 degree respectively. CMIP5_Pr refers to the precipitation outputs of Coupled Model Inter-comparison Project 5 (CMIP5). In this paper, the precipitation outputs of 25 CMIP5 models were majorly studied (detailed information refers to Table 1). DEMp refers to the DEM value at point-scale and GPCC_Prp refers to the GPCC_Pr at point-scale. To display the process of the Moving Random Points algorithm, Fig. 1subA was attached to Fig. 1. Besides, to shed light on the mechanism of bias correction, Fig. 1subB was attached to Fig. 1. And within Fig. 1subB, 4-type of points were selected on behalf of 4-type of precipitation annual distributions (including maximum precipitation happening during January-March, April-June, July-September and October-December) 


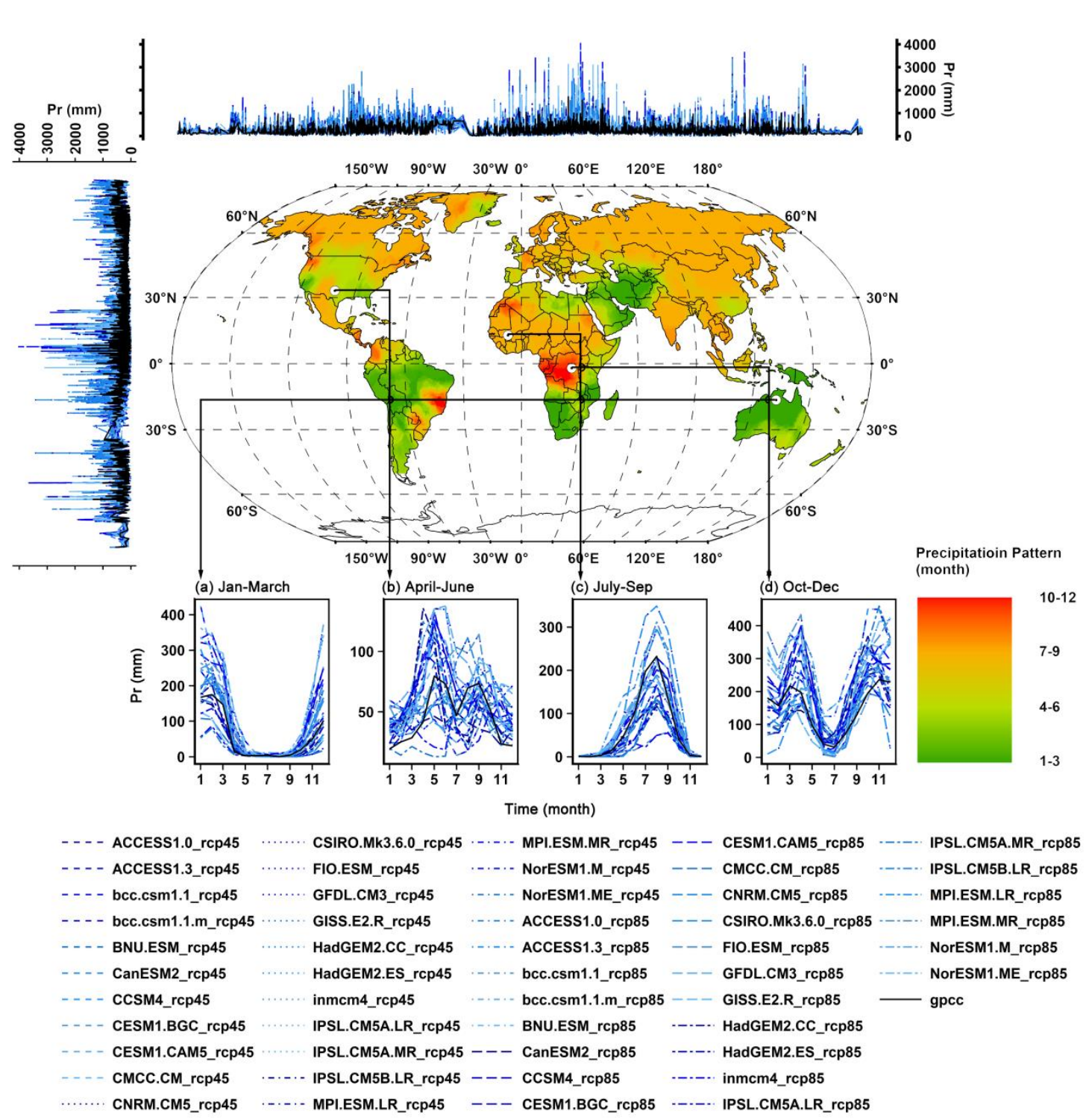

Fig. 2 Global classification of monthly patterns of precipitation and spatial-comparison between the annually maximum value of GPCC precipitation from 1964 to 1999 and the annually maximum value of 25 CMIP5 model precipitation from 2064 to 2099 by longitude and latitude respectively. 

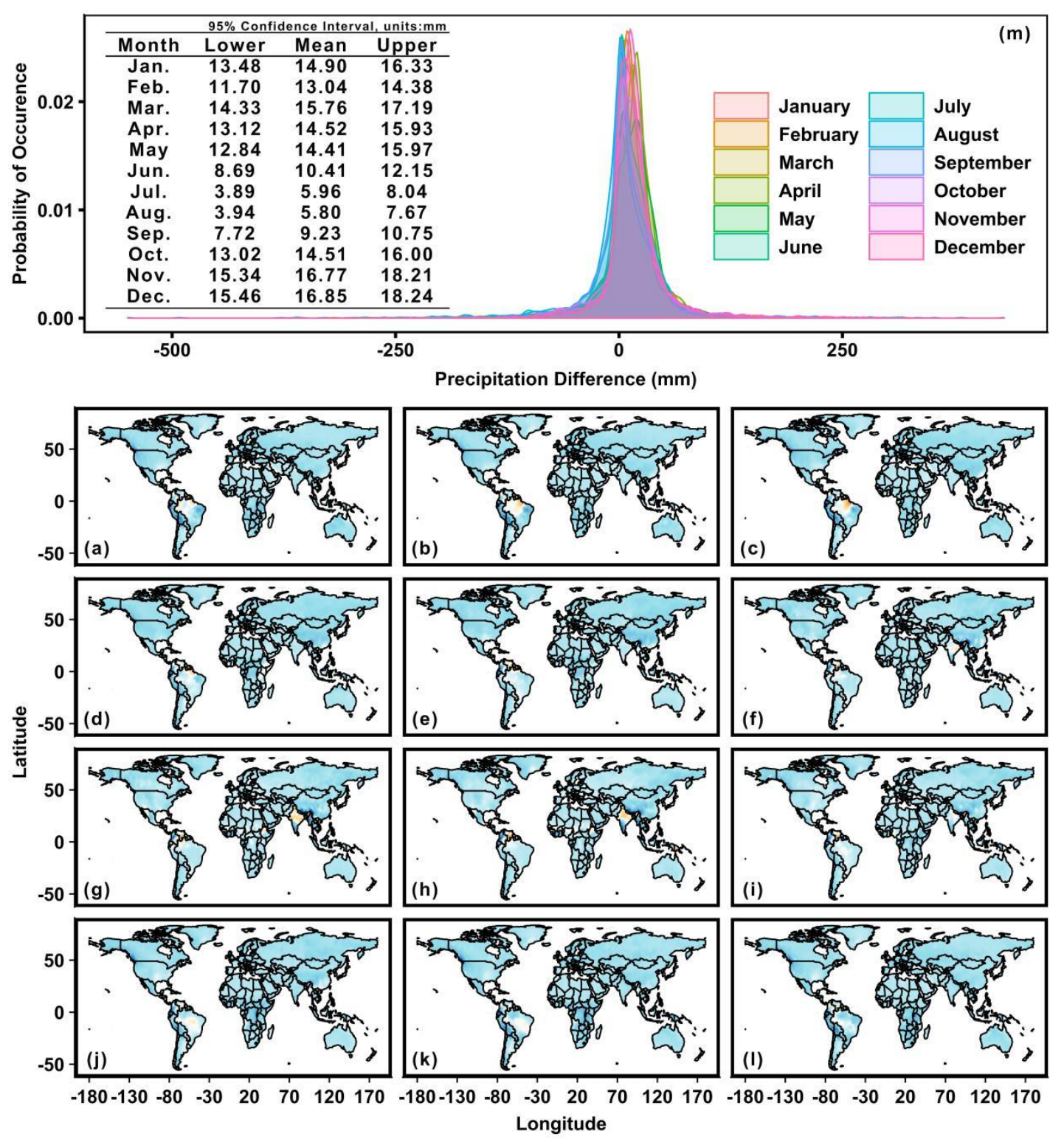

Precipitation Difference $(\mathrm{mm})$

$-400$

$-200$

0

200

400

599

600

601

602

603

604

605

606

607

608

609

610

Fig. 3 Precipitation difference between GPCC monthly-mean precipitation and average values of 25 CMIP5 monthly-mean precipitation outputs under RCP4.5. Figs. 3a-l exhibit spatial distribution of the precipitation difference at the point scale from January to December respectively. Fig. $3 \mathrm{~m}$ sheds lights on the probability distribution considering precipitation differences of all sample points from January to December respectively. Besides, the table within Fig. $3 \mathrm{~m}$ displays the $95 \%$ confidence interval of precipitation difference for each month. 

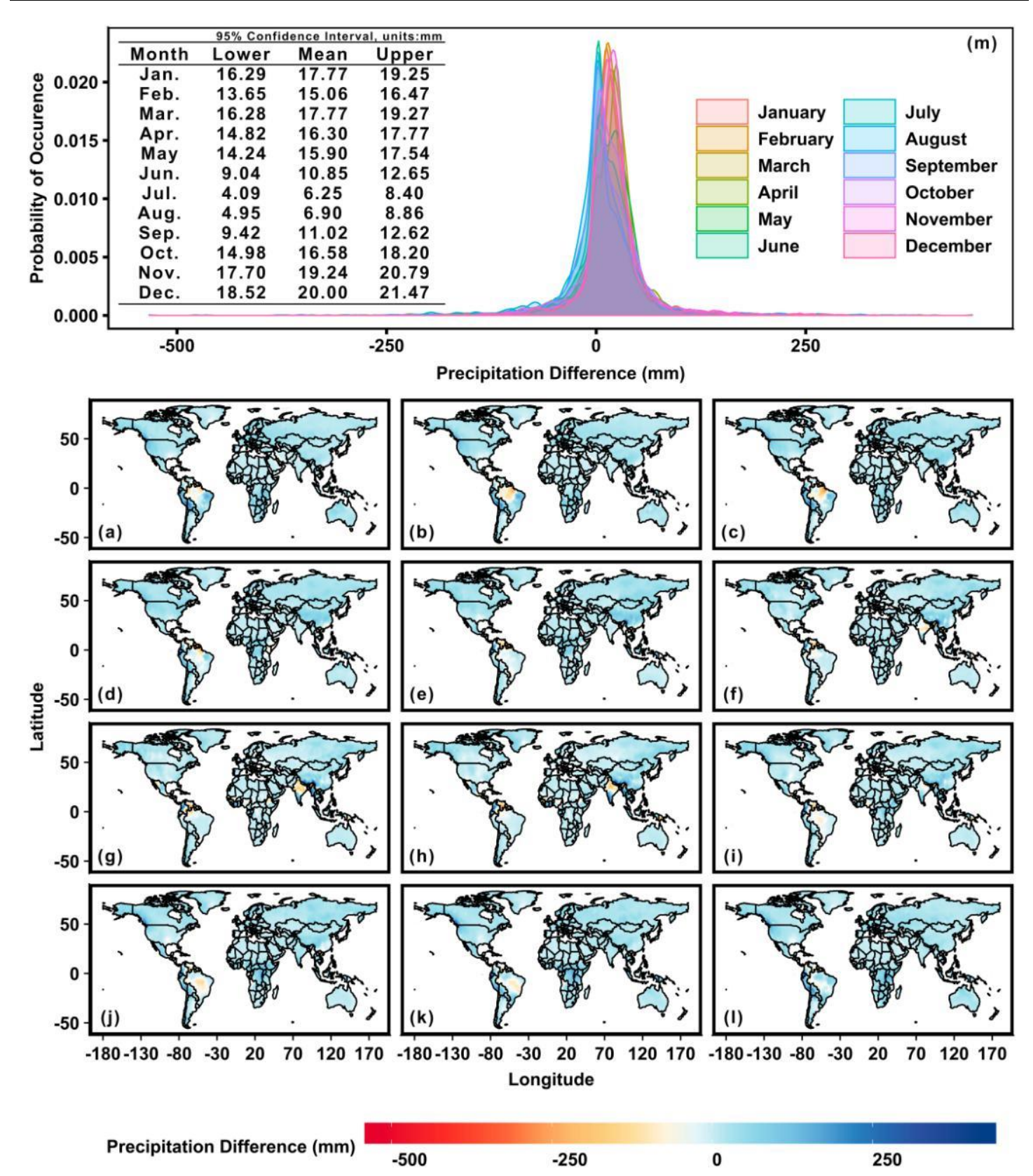

Fig. 4 Precipitation difference between GPCC monthly-mean precipitation and average values of 25 CMIP5 monthly-mean precipitation outputs under RCP8.5. Figs. 4a-1 exhibit spatial distribution of the precipitation difference at the point scale from January to December respectively. And Fig. $4 \mathrm{~m}$ sheds lights on the probability distribution considering precipitation differences of all sample points from January to December respectively. Besides, the table within Fig. $4 \mathrm{~m}$ displays the 95\% confidence interval of precipitation difference for each month. 


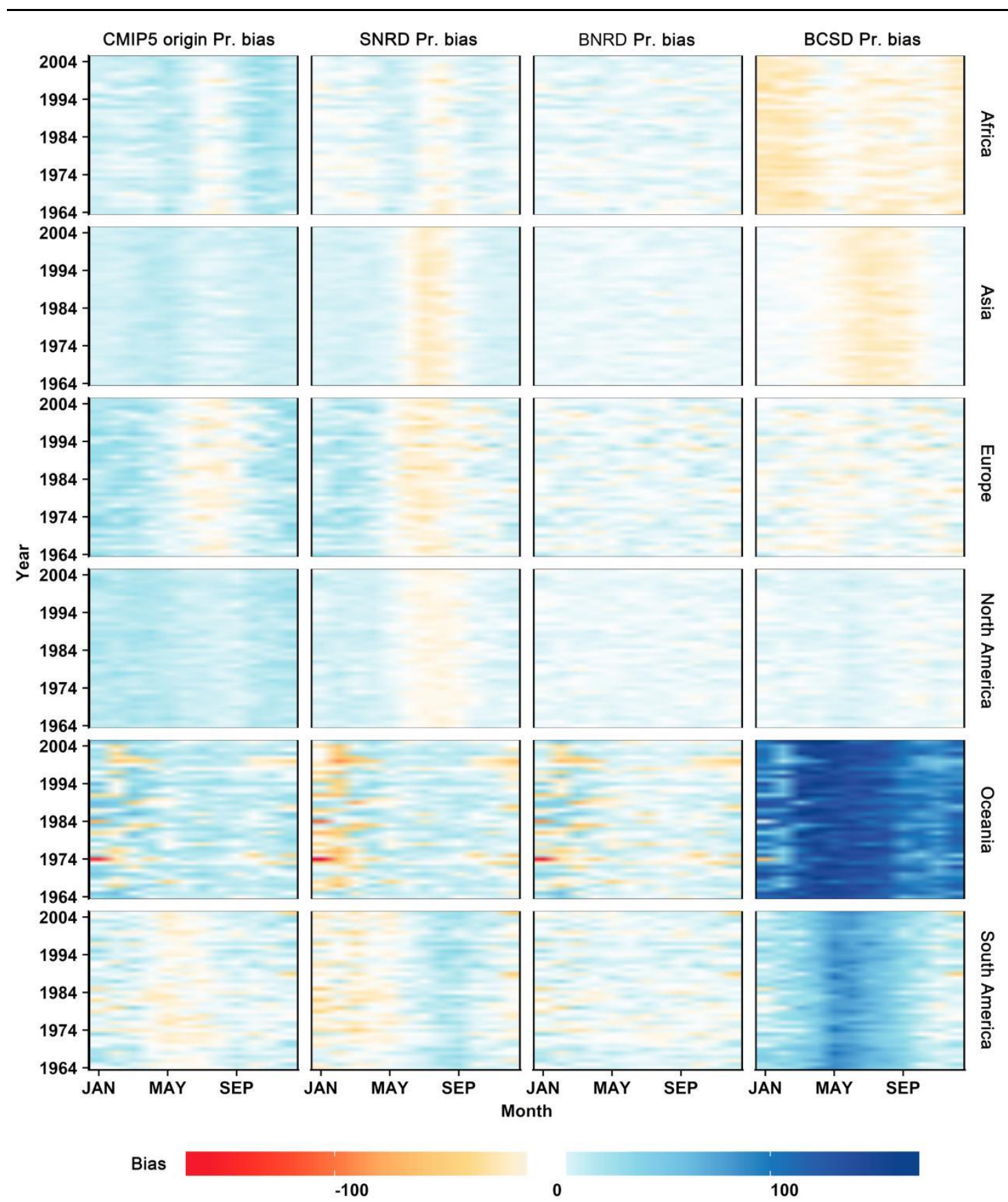

Fig. 5 Intercomparison of bias between average precipitation indices of the original CMIP5 620 precipitation, the BNRD-processed CMIP5 precipitation, BCSD-processed CMIP5 precipitation 621 and GPCC from 1964 to 2005 at monthly scale at the continental scale. 

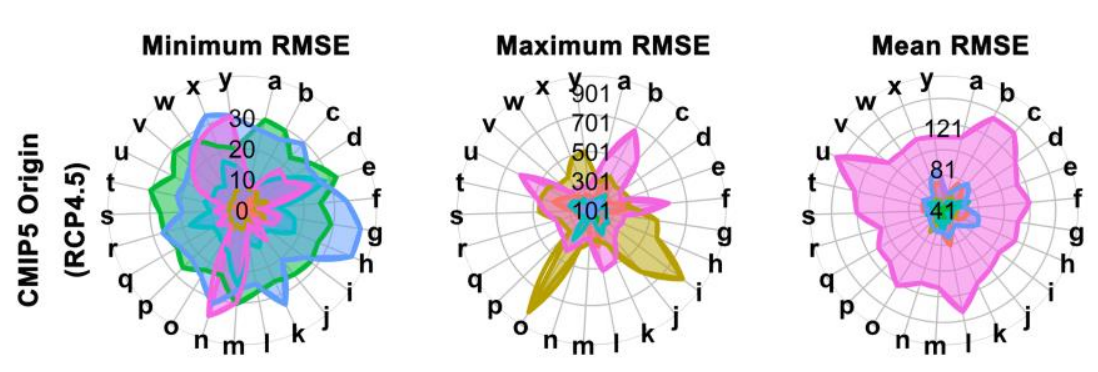

a: ACCESS1-0

b: ACCESS1-3

c: bcc-csm1-1-m

d: bcc-csm1-1
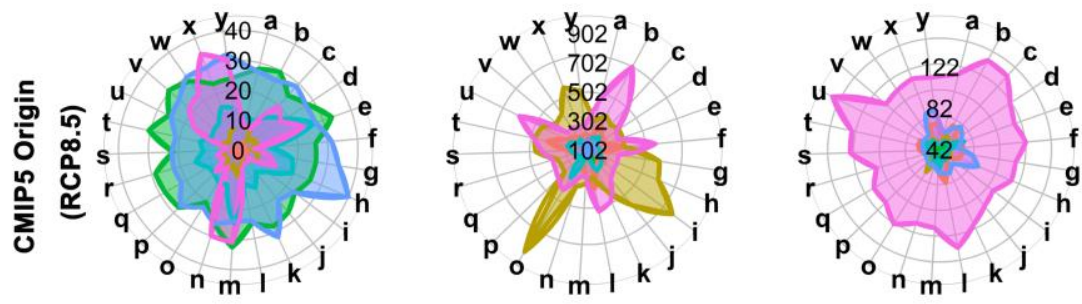

e: BNU-ESM

f: CanESM2

$\mathrm{g}: \operatorname{ccs} M 4$

h: CESM1-BGC

i: CESM1-CAM5
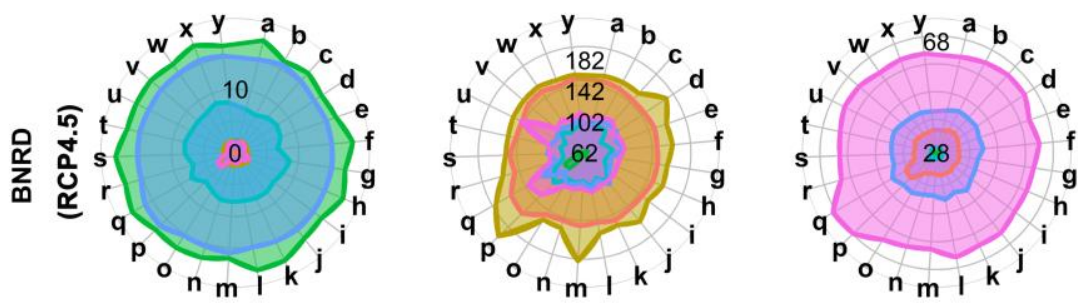

j: CMCC-CM

k CNRM-CM5

I: CSIRO-Mk3-6-0
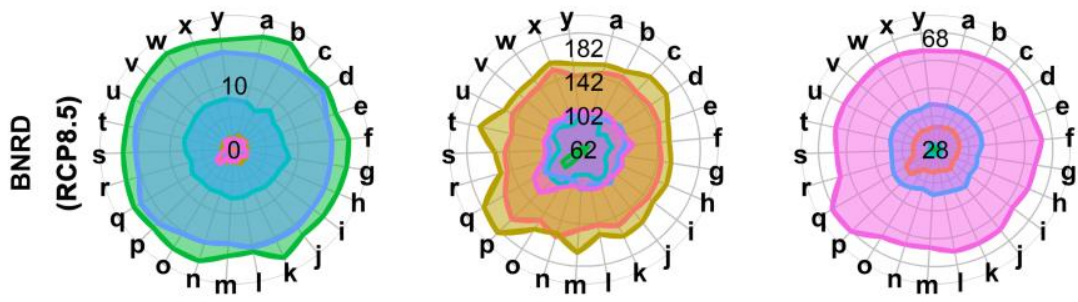

m: FIO-ESM

n: GFDL-CM3

o: GISS-E2-R

p: HadGEM2-CC

q: HadGEM2-ES
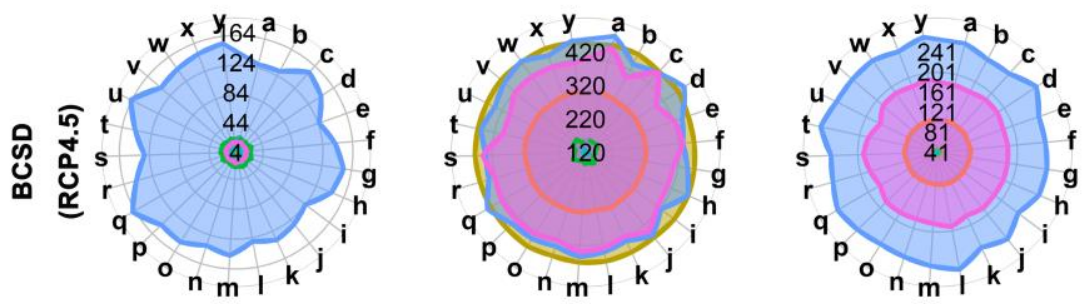

r: inmcm4

s: IPSL-CM5A-LR

t: IPSL-CM5A-MR

u: IPSL-CM5B-LR
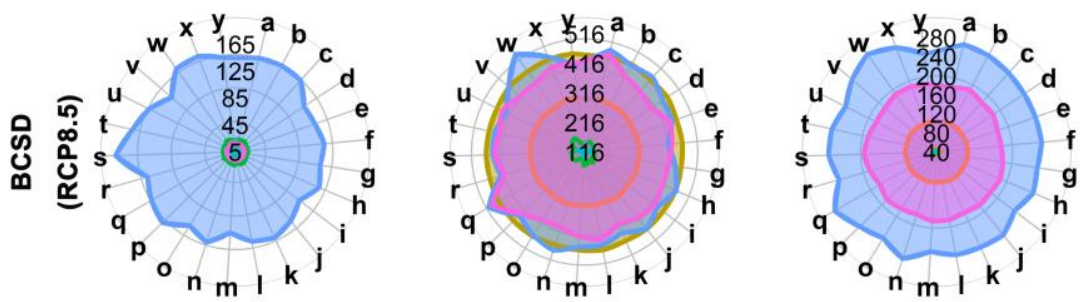

v: MPI-ESM-LR

w: MPI-ESM-MR

x: NorESM1-M

y: NorESM1-ME

Continent

Africa
Asia

Europe

North_America

Oceania

South_America

Fig. 6 Intercomparison of RMSE (root mean square error) among the original SMIP5 precipitation, BNRD- and BCSD-downscaled 25 CMIP5 precipitation outputs on the continent scale under both RCP 4.5 and RCP 8.5 (RCP refers to the Representative Concentration Pathway) scenarios. 

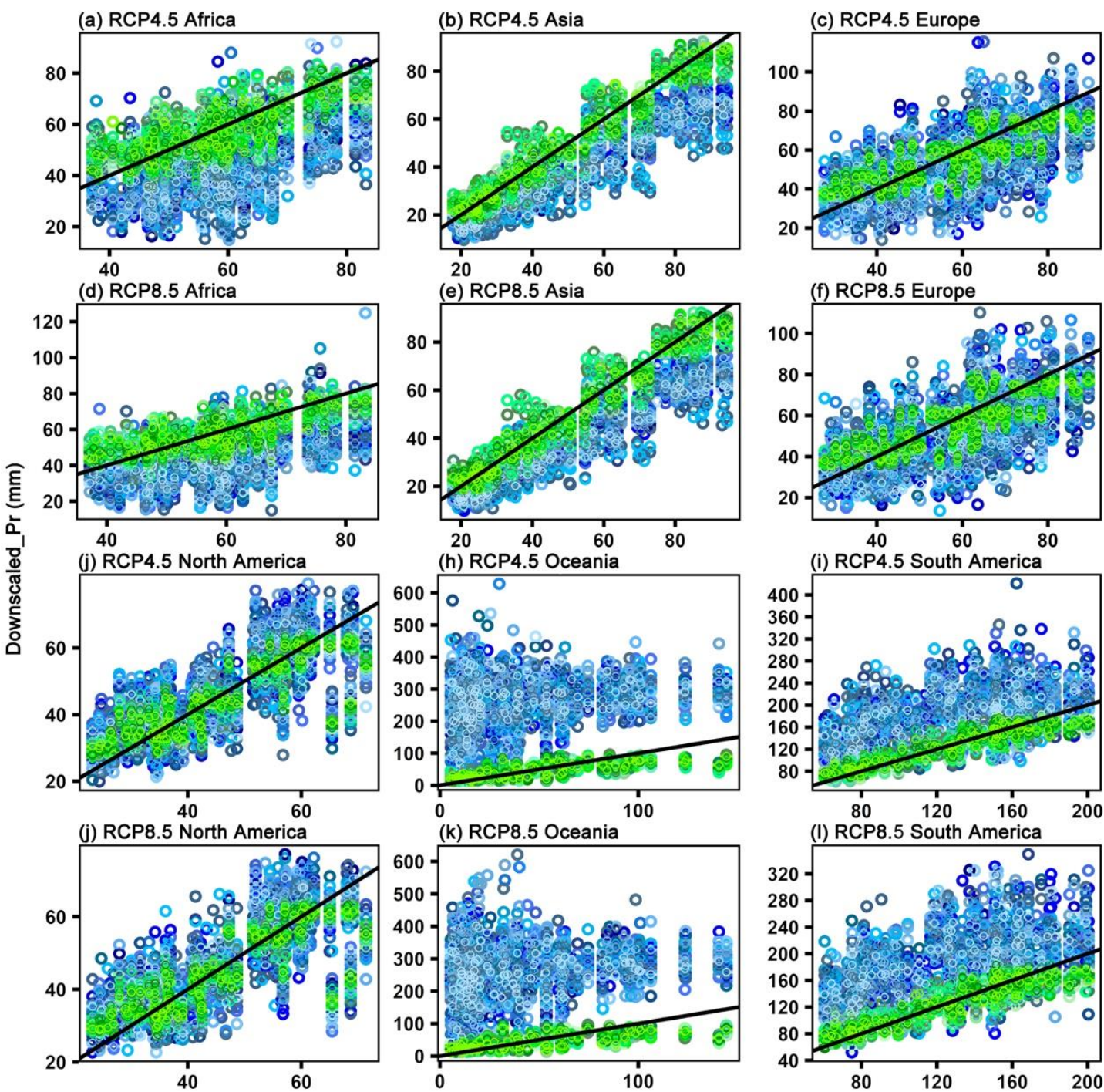

(k) RCP8.5 Oceania
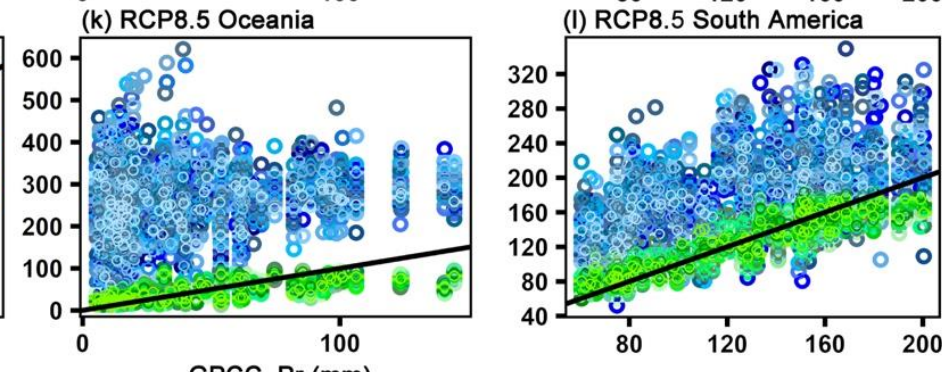
- ACCESS1-0_BCSD ○ CNRM-CM5_BCSD ○ IPSL-CM5B-LR_BCSD
- ACCESS1-3 BCSD O CSIRO-MK3-6-0 BCSD MPI-ESM-LR BCSD
- bCC-CSM1-1_BCSD O FIO-ESM BCSD
- MPI-ESM-MR_BCSD
- bcc-csm1-1-m BCSD $\circ$ GFDL-CM3 BCSD
- NorESM1-M_BCSD
BNU-ESM BCSD $\circ$ GISS-E2-R BCSD
NorESM1-ME BCSD
- CanESM2_BCSD
ACCESS1-0_BNRD
CCSM4_BCSD
- HadGEM2-ES_BCSD
ACCESS1-3 BNRD
CESM1-BGC_BCSD 0 inmcm4_BCSD
- bcc-csm1-1_BNRD
- CESM1-CAM 5 BCSD O IPSL-CM5A-LR_BCSD ○ bcc-csm1-1-m_BNRD
- CMCC-CM BCSD
- IPSL-CM5A-MR BCSD BNU-ESM BNRD
- HadGEM2-CC_BNRD
O CSIRO-Mk3-6-0_BNRD
HadGEM2-ES_BNRD
MPI-ESM-LR_BNRD
inmcm4 BNRD
- GISS-E2-R BNRD
- IPSL-CM5A-LR_BNRD
NorESM1-ME_BNRD
- IPSL-CM5A-MR_BNRD
- IPSL-CM5B-LR_BNRD

Fig. 7 Intercomparison between the BNRD-downscaled 25 CMIP5 precipitation outputs and GPCC indices and intercomparison between BCSD-downscaled 25 CMIP5 precipitation outputs and GPCC indices on the continent scale from 2006 to 2013 (validation period) under both RCP4.5 and RCP8.5 scenarios. 


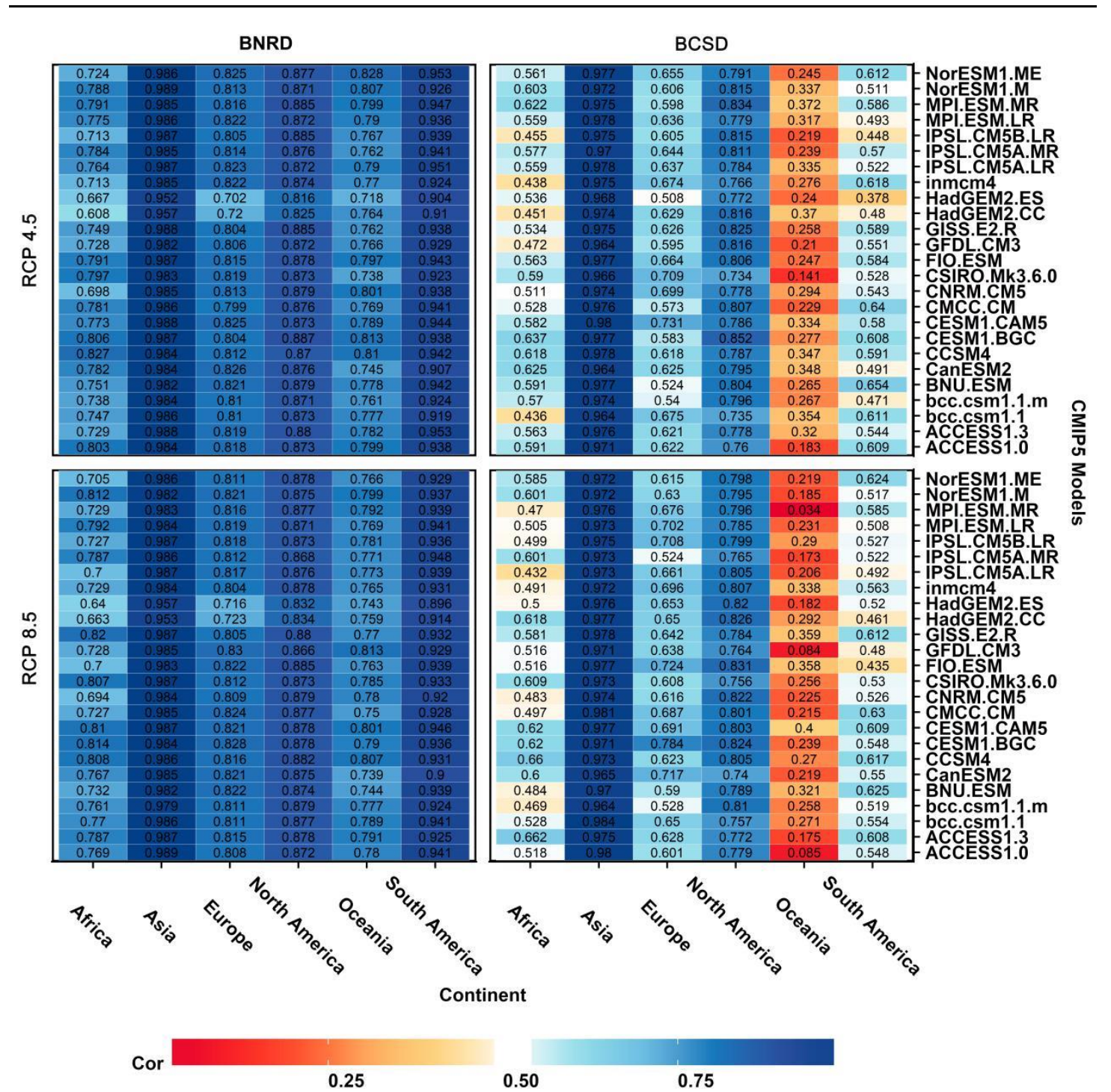

Fig. 8 Intercomparison of the Pearson correlation coefficients between BNRD- and BCSD639 downscaled 25 CMIP5 precipitation outputs and GPCC on the continent scale from 2006 to 2013 640 (validation period) under both RCP4.5 and RCP8.5. Cor refers to correlation coefficients. 


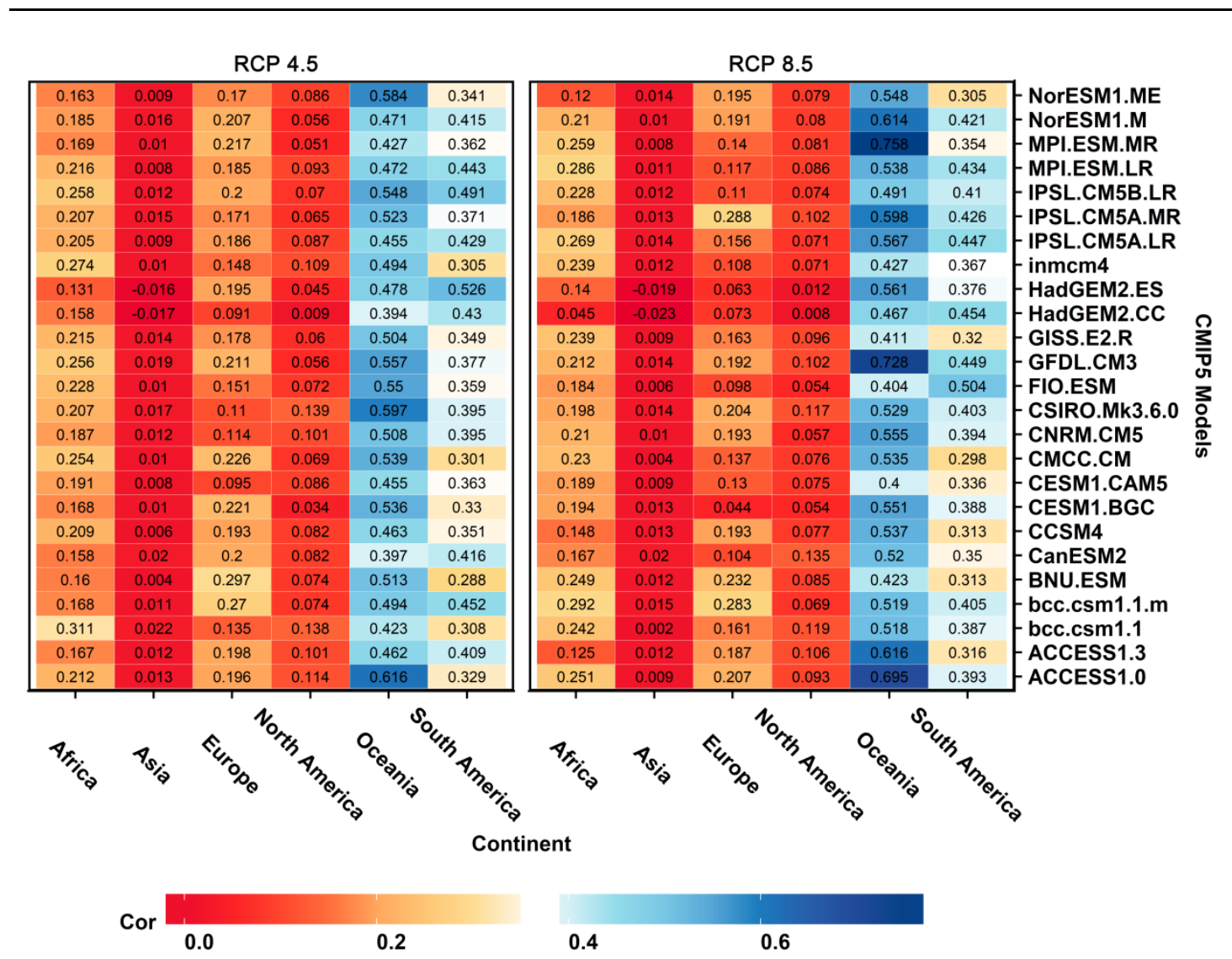

Fig. 9 Difference of the Pearson correlation coefficients between BNRD- and BCSD-downscaled 25 CMIP5 precipitation outputs and GPCC on the continent scale from 2006 to 2013 (validation period) under both RCP4.5 and RCP8.5. Cor refers to correlation coefficients. 

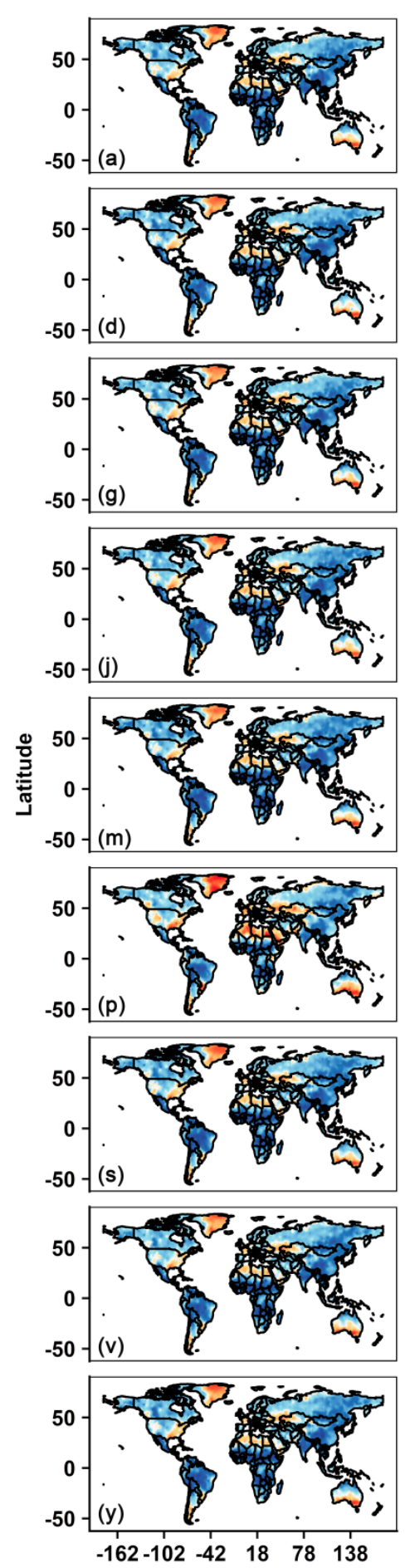

668

669

670

671

672

673

674

Cor (2006-2013).
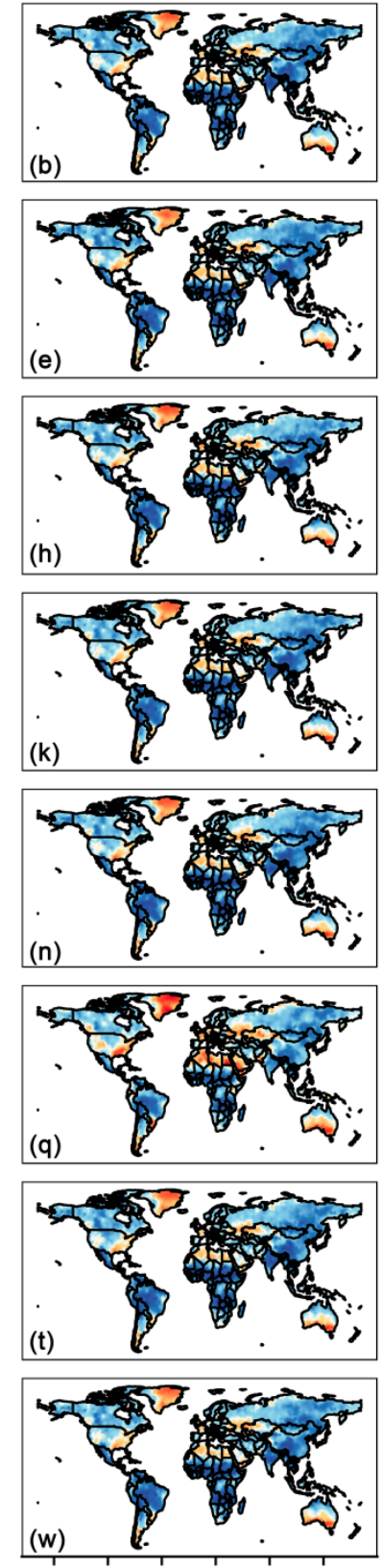

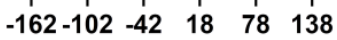

$\begin{array}{ll}\text { (a) ACCESS1-0 (g) CCSM4 } & \text { (b) }\end{array}$

$\begin{array}{ll}\text { (b) ACCESS1-3 } & \text { (h) CESM1-BGC }\end{array}$

$\begin{array}{ll}\text { (c) bcc-csm1-1 } & \text { (i) CESM1-CAM5 }\end{array}$

(d) bcc-csm1-1-m (j) CMCC-CM

$\begin{array}{ll}\text { (e) BNU-ESM } & \text { (k) CNRM-CM5 }\end{array}$

(l) $\mathrm{CSI}$

\section{Longitude}

0.25

0.50

0.75
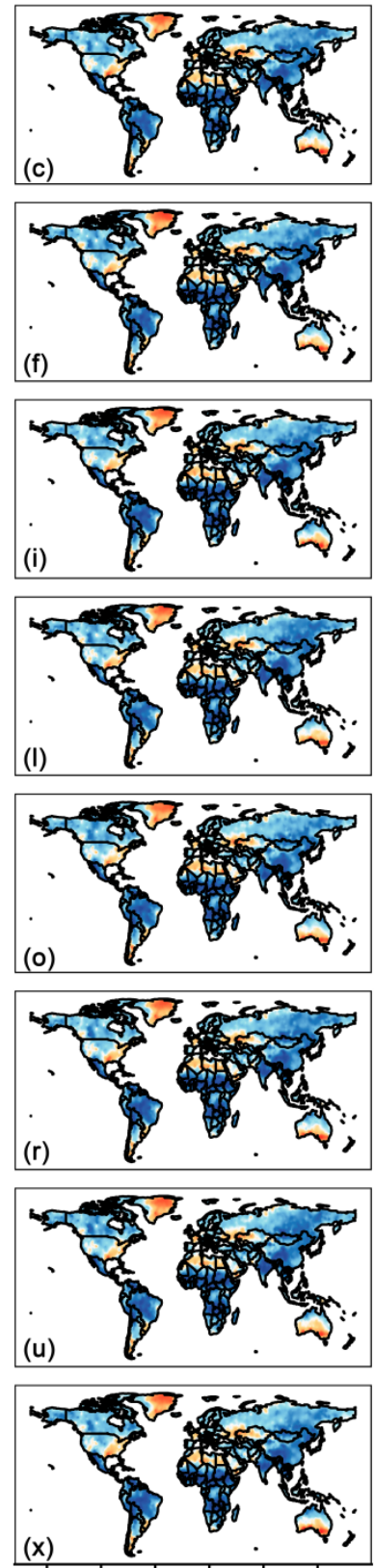

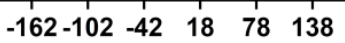

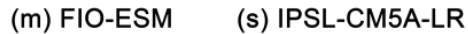

$\begin{array}{ll}\text { (n) GFDL-CM3 } & \text { (t) IPSL-CM5A-MR }\end{array}$

(o) $G I S S=E 2-R \quad$ (u) IPSL-CM5B-LR

(p) HadGEM2-CC (v) MPI-ESM-LR

(q) HadGEM2-ES (w) MPI-ESM-MR

(x) NorESM1-M

(y) NorESM1-ME

Fig. 10 Spatial pattern of Pearson correlation coefficients between GPCC precipitation and 25 CMIP5 models precipitation downscaled by BNRD method under RCP4.5 during validation period 

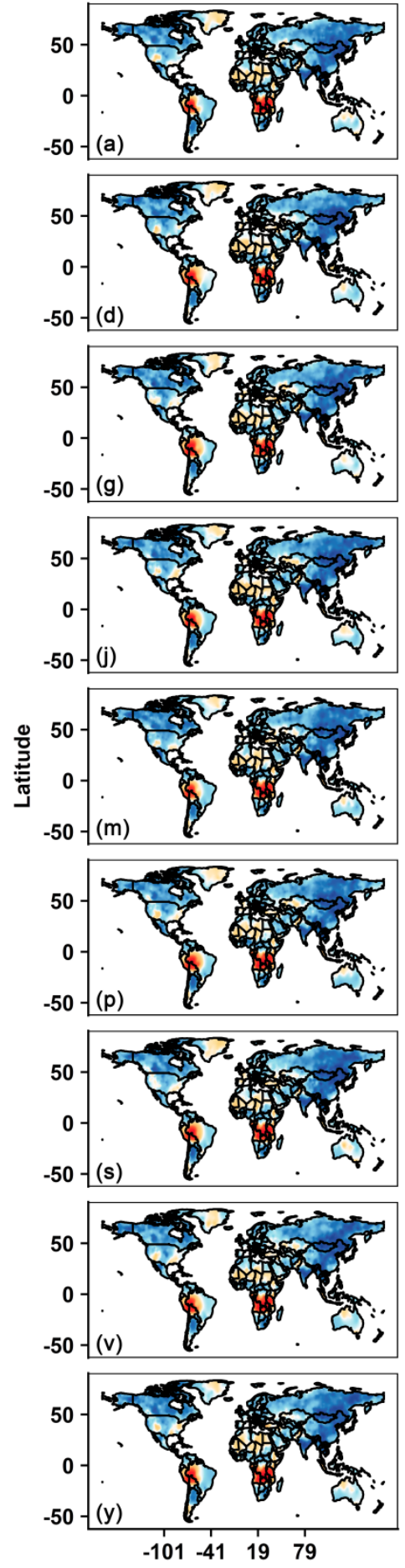

(a) ACCESS1-0 (g) CCSM

(b) ACCESS1-3 (h) CESM1-BGC

$\begin{array}{ll}\text { (c) bcc-csm1-1 } & \text { (i) CESM1-CAM5 }\end{array}$

(d) bcc-csm1-1-m (j) CMCC-CM

$\begin{array}{ll}\text { (e) BNU-ESM } & \text { (k) CNRM-CM5 }\end{array}$

(f) CanESM2

(l) $C$ CSRO-M 3

Longitude

Cor
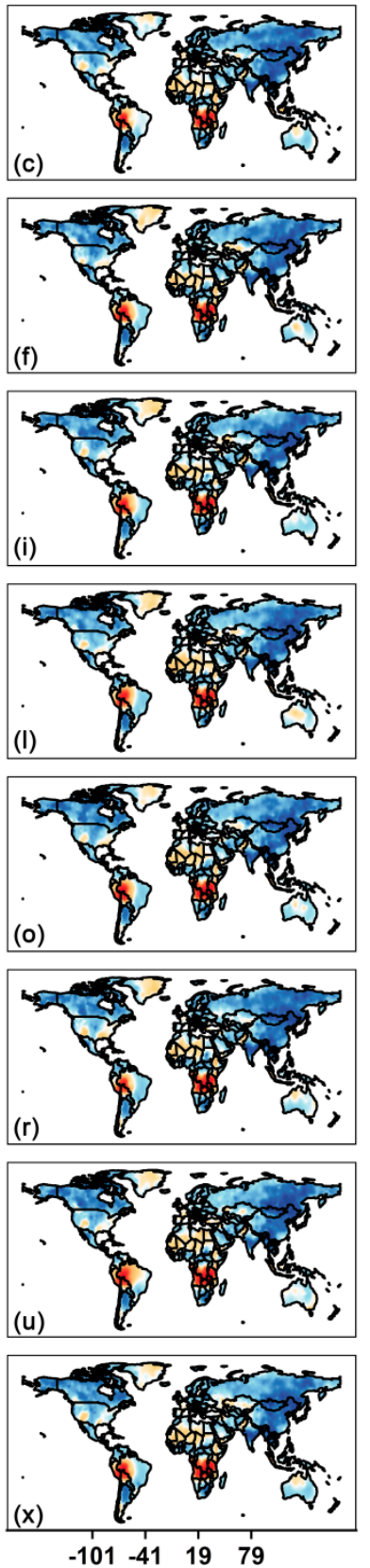

$\begin{array}{ll}\text { (m) FIO-ESM } & \text { (s) IPSL-CM5A-LR }\end{array}$

$\begin{array}{ll}\text { (n) GFDL-CM3 } & \text { (t) IPSL-CM5A-MR }\end{array}$

$\begin{array}{ll}\text { (o) GISS }=E 2-R & \text { (u) IPSL-CM5B-LR }\end{array}$

(p) HadGEM2-CC (v) MPI-ESM-LR

(q) HadGEM2-ES (w) MPI-ESM-MR

(x) NorESM1-M

(y) NorESM1-ME

$-0.5$

0.0

0.5

Fig. 11 Spatial pattern of Pearson correlation coefficients between GPCC precipitation and 25 CMIP5 precipitation downscaled by BCSD method under RCP4.5 during validation period (20062013). 

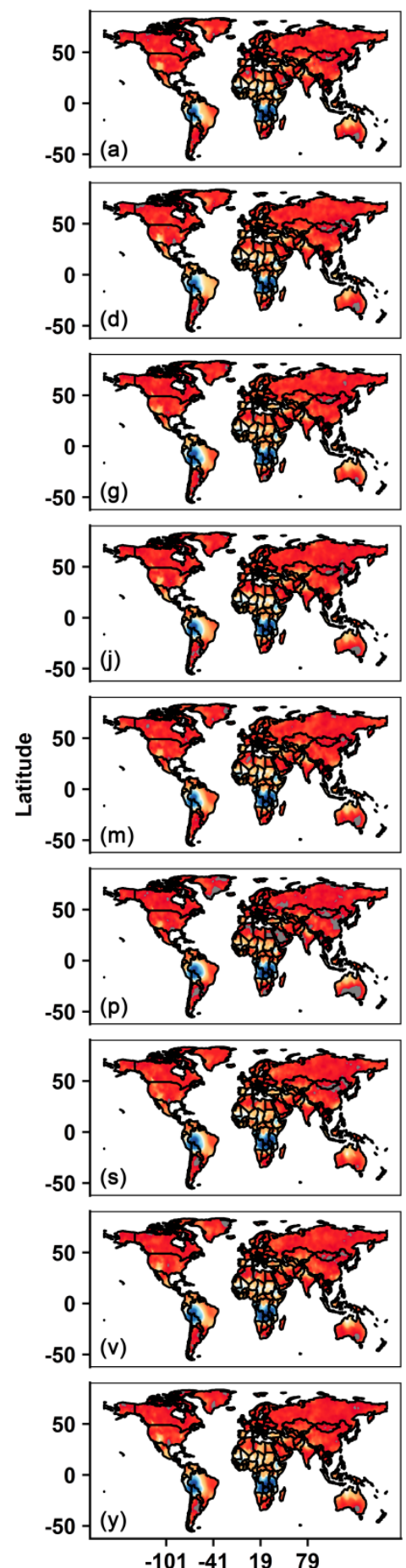

$\begin{array}{ll}\text { (b) ACCESS1-3 } & \text { (h) CESM1-BGC }\end{array}$

$\begin{array}{ll}\text { (c) bcc-csm1-1 } & \text { (i) CESM1-CAM5 }\end{array}$

(d) bcc-csm1-1-m (j) CMCC-CM

(e) BNU-ESM

(k) CNRM-CM5

(l) CSIRO-Mk3-6

Longitude
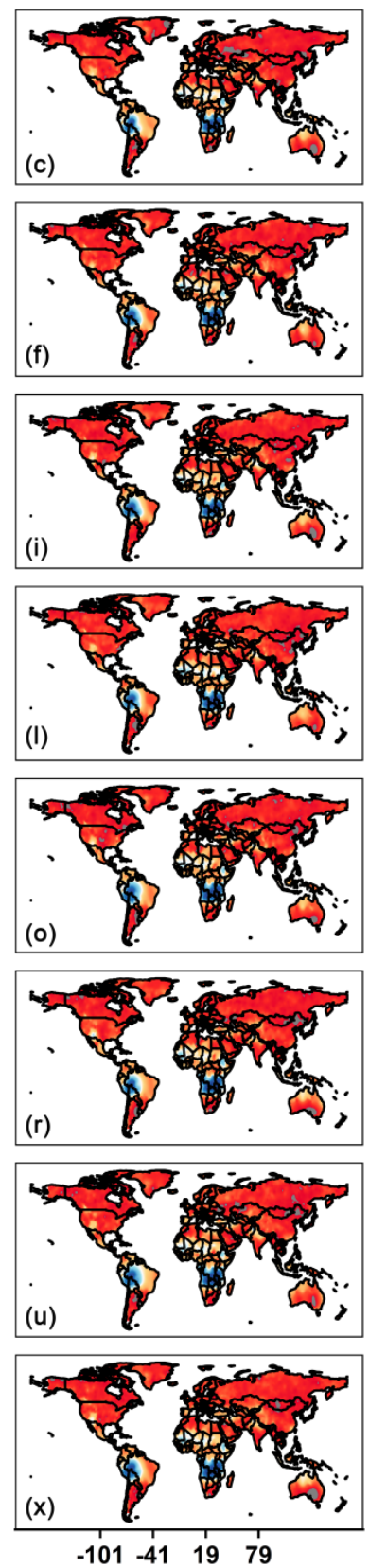

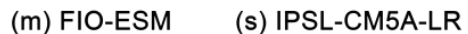

(n) GFDL-CM3 $\quad$ (t) IPSL-CM5A-MR

(o) GISS=E2-R (u) IPSL-CM5B-LR

(p) HadGEM2-CC (v) MPI-ESM-LR

(q) HadGEM2-ES (w) MPI-ESM-MR

(x) NorESM1-M

(y) NorESM1-ME

Cor

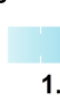



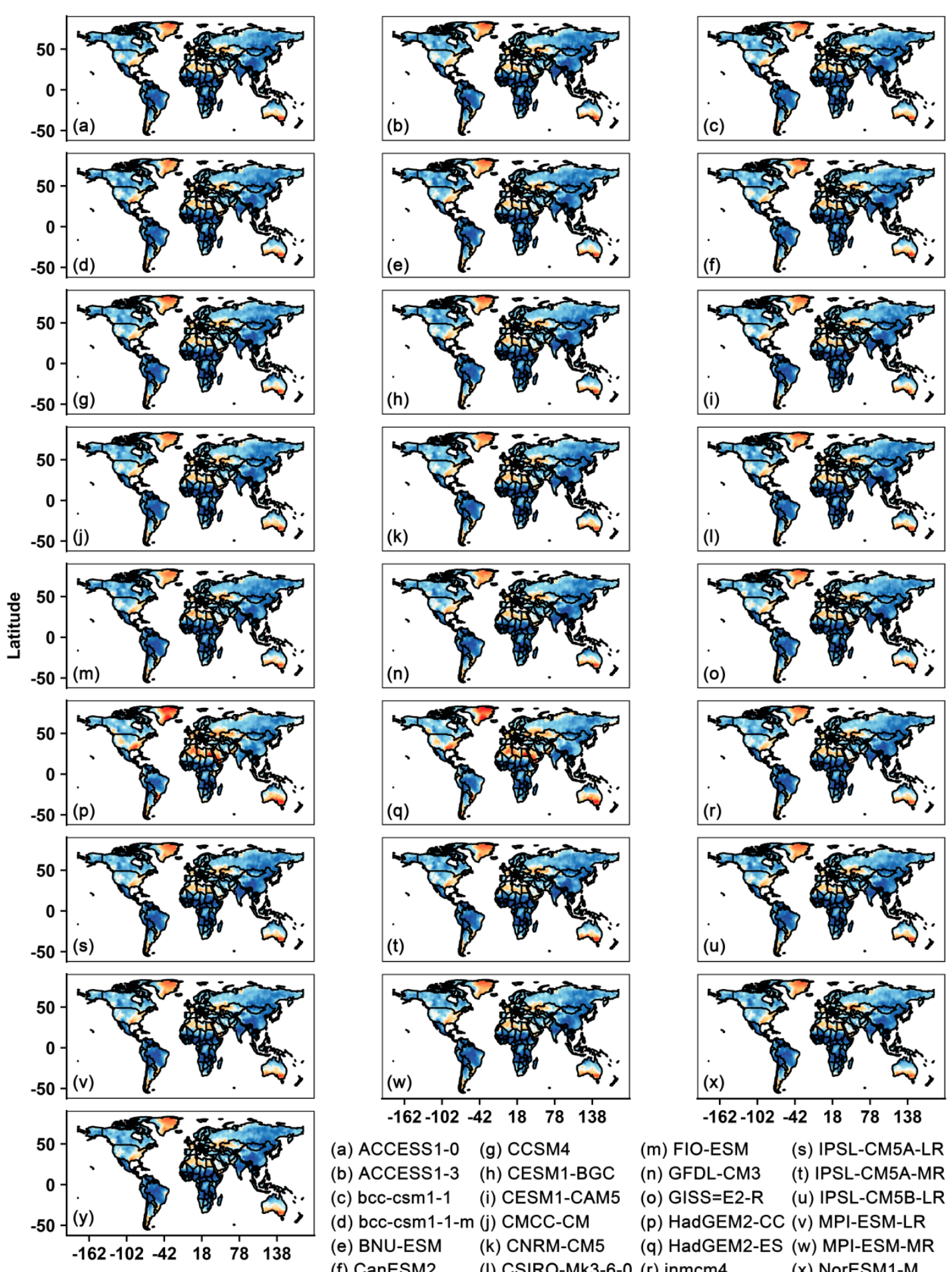
$\begin{array}{ll}\text { (a) ACCESS1-0 } & \text { (g) CCSM4 }\end{array}$
(m) FIO-ESM
(s) IPSL-CM5A-LR

$\begin{array}{ll}\text { (b) ACCESS1-3 } & \text { (h) CESM1-BGC }\end{array}$

$\begin{array}{ll}\text { (c) bcc-csm1-1 } & \text { (i) CESM1-CAM5 }\end{array}$

(d) bcc-csm1-1-m (j) CMCC-CM

$\begin{array}{ll}\text { (e) BNU-ESM } & \text { (k) CNRM-CM5 }\end{array}$

(f) CanESM2

(k) CNRM-Ci

(l)

(n) GFDL-CM3

(t) IPSL-CM5A-MR

(o) GISS=E2-R

(u) IPSL-CM5B-LR

(p) HadGEM2-CC (v) MPI-ESM-LR

\section{Longitude}

(q) HadGEM2-ES (w) MPI-ESM-MR

(x) NorESM1-M

(y) NorESM1-ME

Cor

0.25

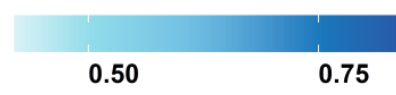

Fig. 13 Spatial pattern of Pearson correlation coefficients between GPCC precipitation and 25 CMIP5 precipitation downscaled by BNRD method under RCP4.5 during period for model validation (2006-2013). 

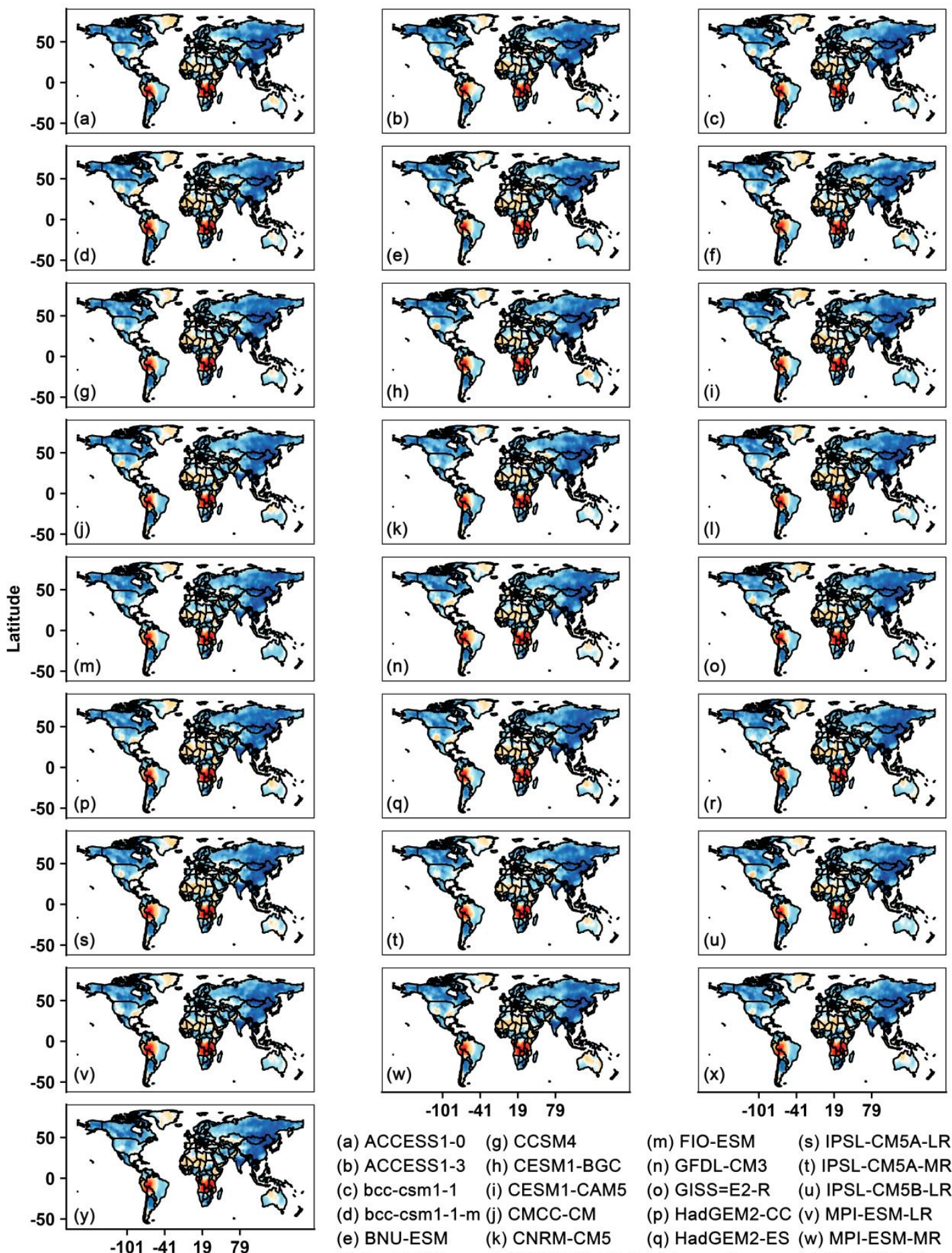

$\begin{array}{ll}\text { (a) ACCESS1-0 } & \text { (g) CCSM4 }\end{array}$

\section{$\begin{array}{ll}\text { (b) ACCESS1-3 } & \text { (h) CESM1-BGC }\end{array}$}

$\begin{array}{ll}\text { (c) bcc-csm1-1 } & \text { (i) CESM1-CAM5 }\end{array}$

(d) bcc-csm1-1-m (j) CMCC-CM

$\begin{array}{ll}\text { (e) BNU-ESM } & \text { (k) CNRM-CM5 }\end{array}$

(f) CanESM2

(I) CSIRO-Mk3-6-0 (r) inmcm4

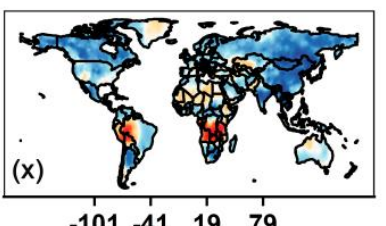

$\begin{array}{llll}-101 & -41 & 19 & 79\end{array}$

$\begin{array}{ll}\text { (m) FIO-ESM } & \text { (s) IPSL-CM5A-LR }\end{array}$

$\begin{array}{ll}\text { (n) GFDL-CM3 } & \text { (t) IPSL-CM5A-MR }\end{array}$

(o) GISS=E2-R $\quad$ (u) IPSL-CM5B-LR

(p) HadGEM2-CC (v) MPI-ESM-LR

(q) HadGEM2-ES (w) MPI-ESM-MR

Longitude

(x) NorESM1-M

(y) NorESM1-ME

Cor

$-0.5$

0.0

0.5

Fig. 14 Spatial pattern of Pearson correlation coefficients between GPCC precipitation and 25 CMIP5 precipitation downscaled by BCSD method under RCP8.5 during period for the model validation (2006-2013). 

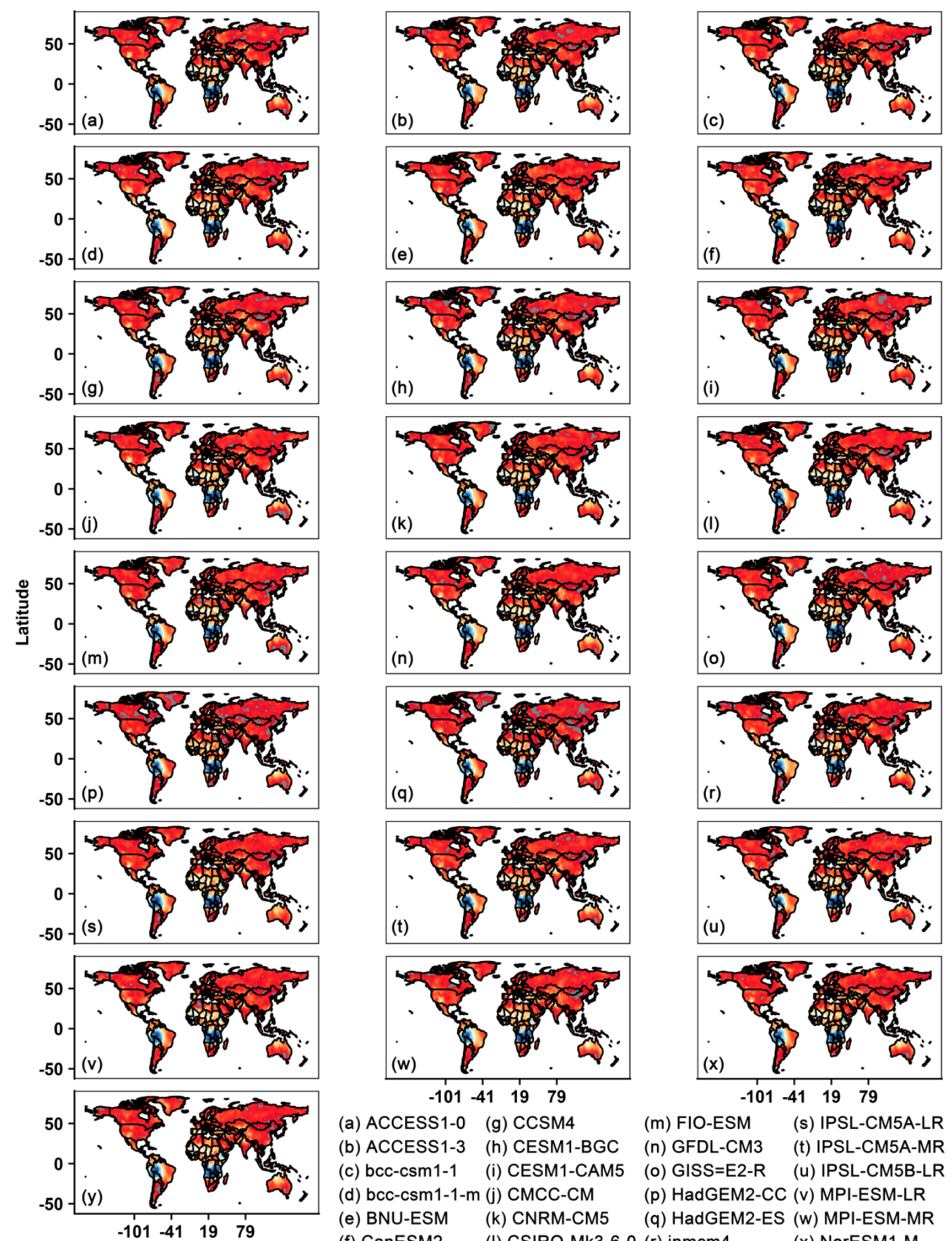
$\begin{array}{ll}\text { (a) ACCESS1-0 } & \text { (g) CCSM4 }\end{array}$

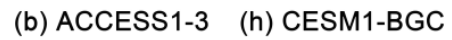

$\begin{array}{ll}\text { (c) bcc-csm1-1 } & \text { (i) CESM1-CAM5 }\end{array}$

(d) bcc-csm1-1-m (j) CMCC-CM

$\begin{array}{ll}\text { (e) BNU-ESM } & \text { (k) CNRM-CM5 }\end{array}$

(f) CanESM2

(l) CSIRO-Mk3-6-0

Longitude

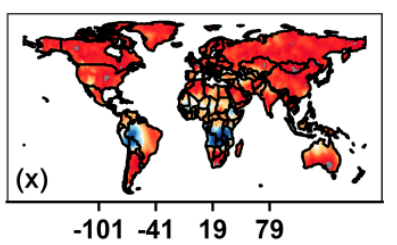

(m) FIO-ESM

(s) IPSL-CM5A-LR

$\begin{array}{ll}\text { (n) GFDL-CM3 } & \text { (t) IPSL-CM5A-MR }\end{array}$

(o) GISS=E2-R (u) IPSL-CM5B-LR

(p) HadGEM2-CC (v) MPI-ESM-LR

$\begin{array}{ll}\text { (q) HadGEM2-ES (w) MPI-ESM-MR } \\ \text { (r) inmcm4 } & \text { (x) NorESM1-M }\end{array}$

(y) NorESM1-ME

Cor

Fig. 15 Spatial pattern of difference of the Pearson correlation coefficients between BNRDdownscaled CMIP5 precipitation and GPCC minus that between BCSD-downscaled precipitation and GPCC under RCP8.5 during the period for model validation (2006-2013). 


\begin{tabular}{|c|c|c|c|}
\hline Index & Model & Latitude & Longitude \\
\hline 1 & ACCESS 1.0 & 1.25 & 1.875 \\
\hline 2 & ACCESS 1.3 & 1.25 & 1.875 \\
\hline 3 & BCC-CSM1.1 & 2.7906 & 2.8125 \\
\hline 4 & BCC-CSM1.1(m) & 2.7906 & 2.8125 \\
\hline 5 & BNU-ESM & 2.7906 & 2.8125 \\
\hline 6 & CCSM4 & 0.9424 & 1.25 \\
\hline 7 & CESM1(BGC) & 0.9424 & 1.25 \\
\hline 8 & CESM1(CAM5) & 0.9424 & 1.25 \\
\hline 9 & CMCC-CM & 0.7484 & 0.75 \\
\hline 10 & CNRM-CM5 & 1.4008 & 1.40625 \\
\hline 11 & CSIRO-Mk3.6.0 & 1.8653 & 1.875 \\
\hline 12 & CanESM2 & 2.7906 & 2.8125 \\
\hline 13 & FIO-ESM & $3.75^{\circ}$ & $1.8947^{\circ}$ \\
\hline 14 & GFDL-CM3 & 2 & 2.5 \\
\hline 15 & GISS-E2-R & 2 & 2.5 \\
\hline 16 & HadGEM2-CC & 1.25 & 1.875 \\
\hline 17 & HadGEM2-ES & 1.25 & 1.875 \\
\hline 18 & INM-CM4 & 1.5 & 2 \\
\hline 19 & IPSL-CM5A-LR & 1.8947 & 3.75 \\
\hline 20 & IPSL-CM5A-MR & 1.2676 & 2.5 \\
\hline 21 & IPSL-CM5B-LR & 1.8947 & 3.75 \\
\hline 22 & MPI-ESM-LR & 1.8653 & 1.875 \\
\hline 23 & MPI-ESM-MR & 1.8653 & 1.875 \\
\hline 24 & NorESM1-M & 1.8947 & 2.5 \\
\hline 25 & NorESM1-ME & 1.8947 & 2.5 \\
\hline
\end{tabular}

705 